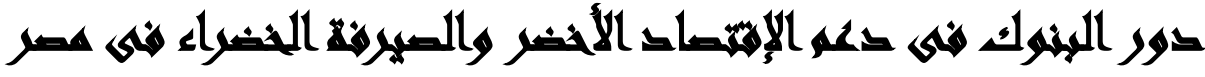

\section{[iv]}

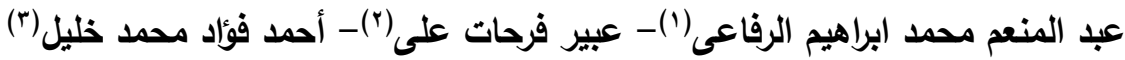

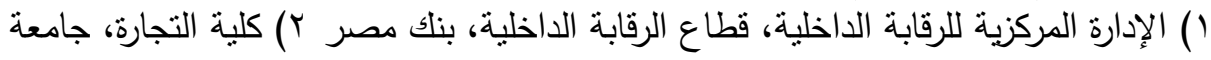

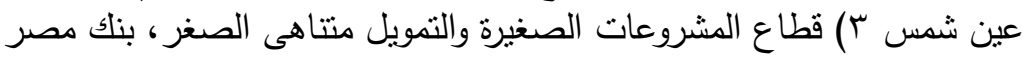

\section{المستحلص}

هدفت الدراسة الى تحديد مفهوم وخصائص ومزايا الانتقال الى الإقتصاد الأخضر

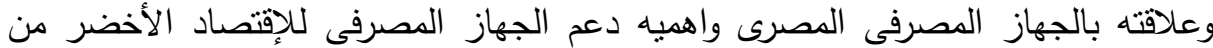

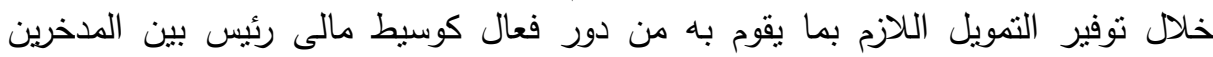

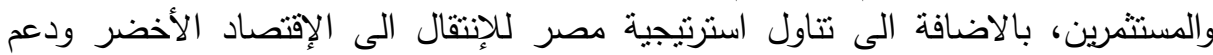

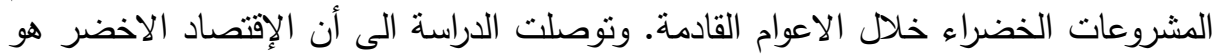

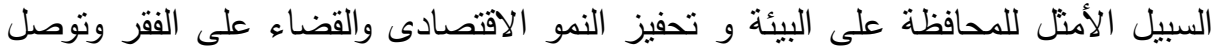

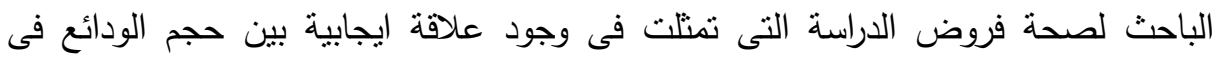

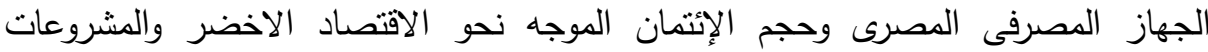

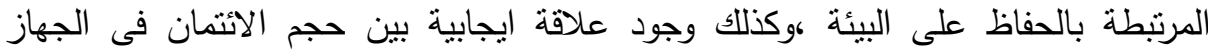

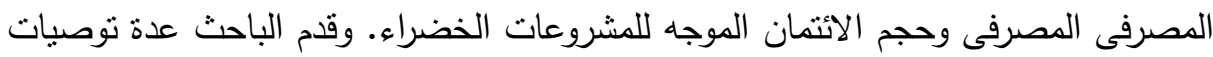

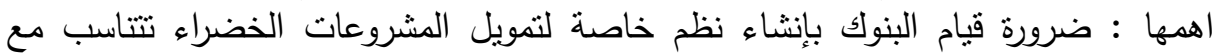

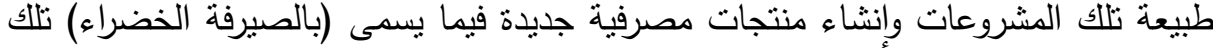
المنتجات محفزة للعملاء للمساهمة فى تمويل تلك المشروعات منل الصناء الصناديق الخضراء التهاء

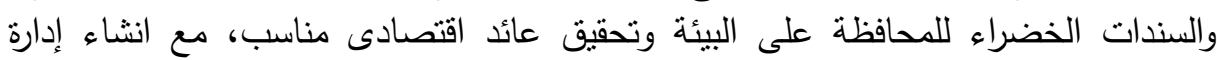

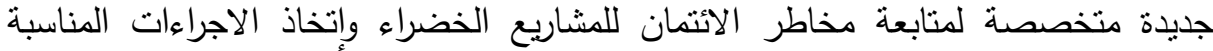

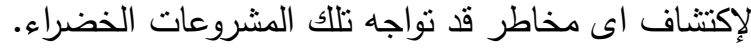
الكلمات المفتاحية: البنوك - الاقتصاد الاخضر - الصيرفة الخضراء التراء . 


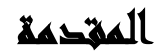

شهد العالم خلال السنوات الماضية عدم استقرار في أسواق الطاقة والسلع الأساسية، ونقص في الأغذية العالمية وندرة في المياه وطغت عليها أزمة مالية واقتصادية لا نزال أثارها

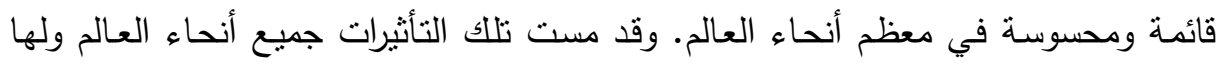
انعكاسات محددة على تحقيق التتمية المستدامة وبلوغ الأهداف الإنمائية للألفية، وتمثّل هذه وله المخاطر الاقتصادية والاجتماعية والبيئية تهديدات خطيرة على أجيالنا المقبلة. على الرغم من الأوضـاع غير المستقرة التي تمر بها المنطقة، سياسياً واجتماعياً واقتصادياً، لكن التحول إلى الاقتصاد الأخضر يمكن أن بساعد في نقل العالم العربي إلى لى فئي

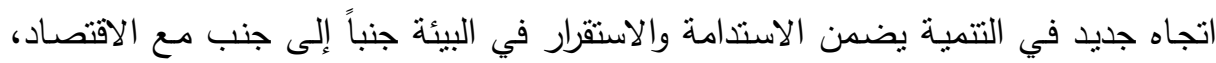
حيث تتحمور المبادئ الأساسية للاقتصاد الأخضر حول إعطاء وزن منساو للتنمية الاقتصادية والعدالة الاجتماعية والاستدامة البيئية، وتلبية هذه الأهداف الثلاثة توفر أساسا لأساء

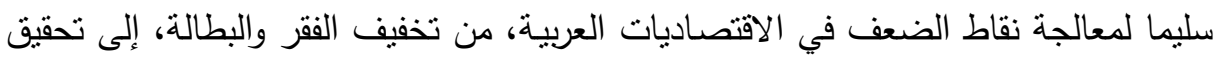

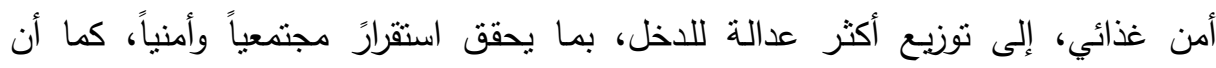
الاستخدام الكفء للأصول الطبيعية من أجل تتويع الاقتصاد، الذي يمثل آلية وركيزة أساسية

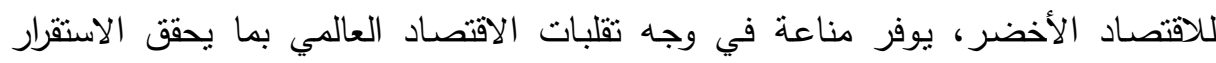
الاقتصادي الغائب عن كثير من مجتمعاتتا. إن مفهوم الاقتصاد الأخضر لا يحل محل مفهوم التتمية المستدامة، ولكنه نتيجة الاقتناع المتزايد بأن تحقيق التتمية المستدامة المطلوبة لن تتحقق إلا عن طريق الترويج لفكرة الاقتصاد الأخضر بعد عقود من تدمير البيئة عن طريق (الاقتصاد البني) وهذا المصطلح

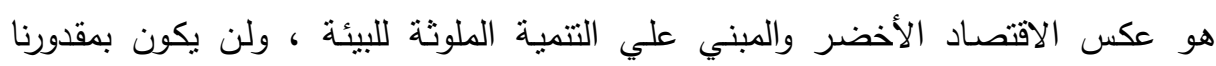
تحقيق الأهداف التتموية للألفية دون تحقيق الاستدامة التي تعتمد بدورها علي فكرة الاقتصاد

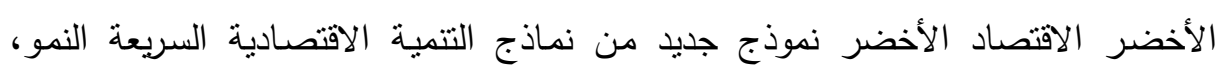

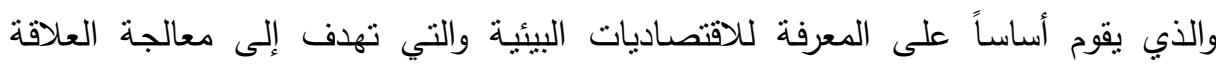
المنبادلة ما بين الاقتصاديات الإنسانية والنظام البيئي الطبيعي، والأثر العكسي للنشاطات النيات

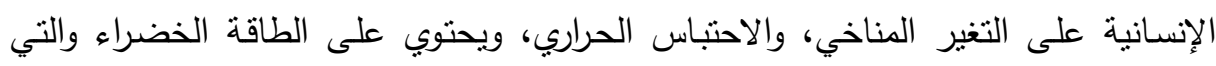


يقوم توليدها على أسـاس الطاقـة المتجددة، بـدلا مـن الوقود الأحفوري، والمحافظـة على

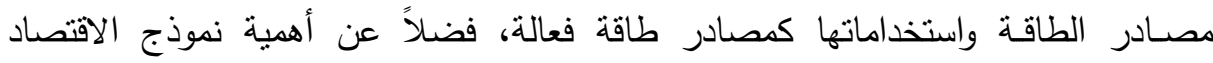

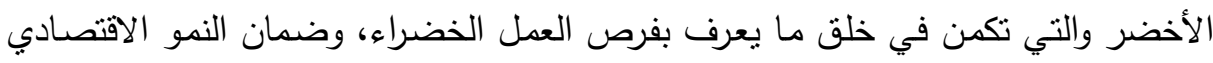
المستدام والحقيقي، ومنع التلوث البيئي، والاحتباس الحراري، واستتزاف الموارد والتراجع البيئي

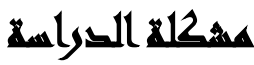

تعد البنوك من اهم تللك القطاعات حيث يعد الجهاز المصرفى عصب الاقتصاد القومى

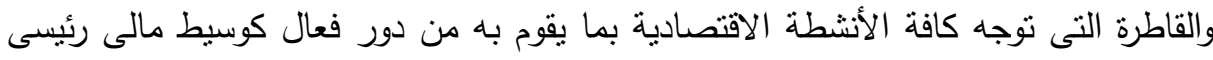
بين المدخرين والمستثرين وتعد السياسات المالية والتى ينم تتفيذها عبر الجهاز المصرفى

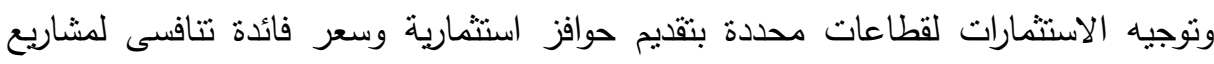
مهتمة او مخصصة للمحافظة على البيئة من العوامل شديدة التاثير على توجيه القطاعات الاقتصادية الى الانشطة المستهدفة لتحقيق معدلات النمو المطلوبة على مستوى الدولة ككل .

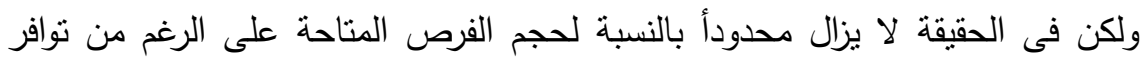
السيولة بالجهاز المصرفى بمعدلات غير مسبوقة ولكن حلقة الوصل بين حجم الودائع بالجهاز المصرفى وحجم التمويل البيئى من وجهه نظر الباحث لا نزال مفقودة وهو ما دعى الباحث

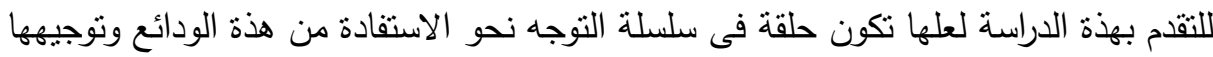

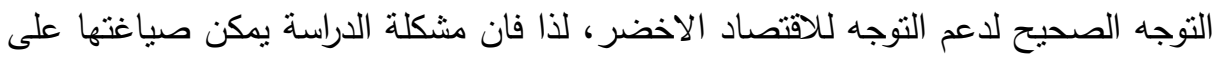
النحو التالى: ما مدى مساهمة القطاع المصرفى في تمويل ودعم التوجه نحو الاقتصاد الاخضر وتمويل المشروعات التى تهدف للمحافظة على البيئة والصيرفة الخضراء في مصر.

\section{أهمية التوراسة}

تستمد هذه الدراسة أهميتها من الناحيتين النظرية والتطبيقية من الأسباب التالية:1- بعد مراجعة المكتبات العربية والأبحاث المنشورة توصل الباحث إلي أن موضوع الجهاز

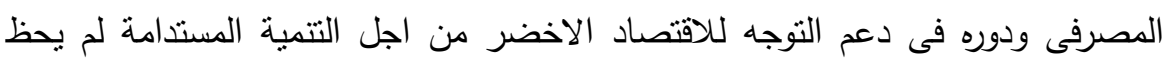

$$
\text { المجلد الثامن والأربعون، الجزء الثانى، ديسمبر } 9 \text { 1 أr }
$$


بالاهتمام الكافى من الدراسات العربية على وجه الخصوص، على الرغم من اهميته البالغة على الصعيد المحلى والصعيد الدولى ولما له من اثار على الاقتصاد القومى ككل.

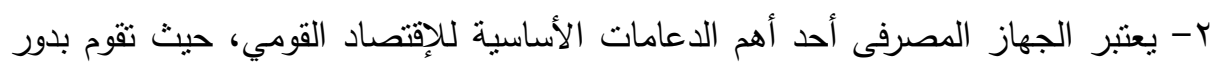

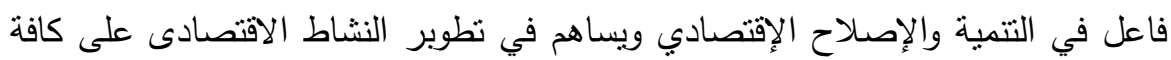
المستويات لذلك يسعى الباحث لعمل دراسة متخصصة نوضح اهمية ذلك الدور لتوجيه كافة القطاعات الاقتصادية لتحقق التتمية الثاملة عن طريق التوجه للاقتصاد الاخضر

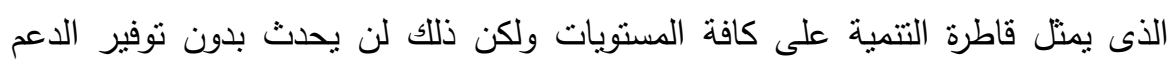
المالى المتمثل فى التمويل الاخضر حتى نتحقق كافة الوفورات بناءاً على الدراسة التى قام لهام بها برنامج الامم المتحدة السابق الاثارة اليه.

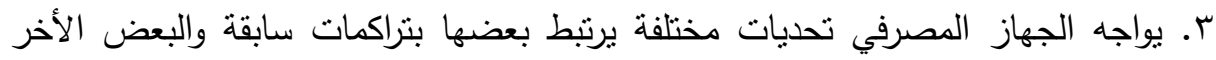

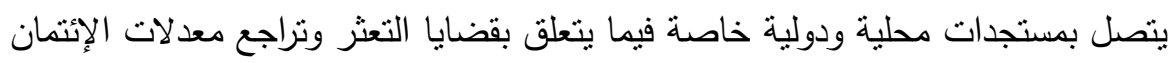
المصرفي، يضاف إلي ذلك ان القطاع المصرفى يعانى من تكس المدخرات على وجه العموم وخصوصاً خلال فترة الدراسة وزاد من مشكلة تكدس المدخرات قرار تعويم الجنيه

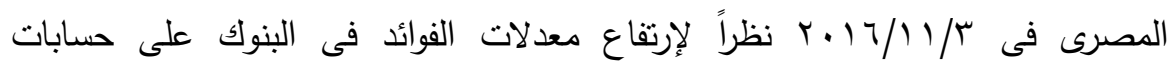

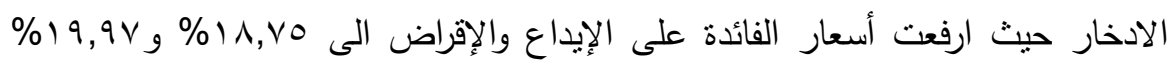

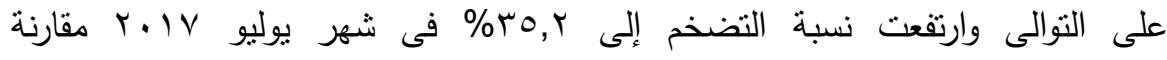

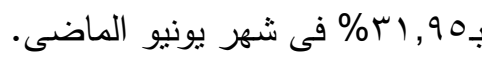

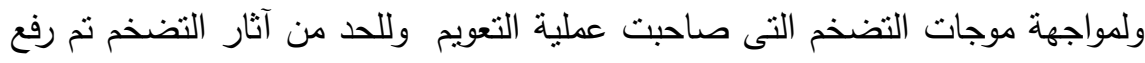

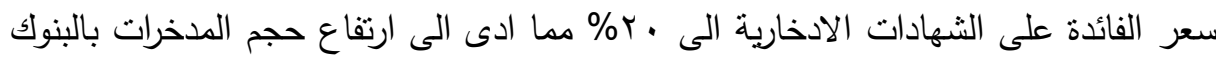

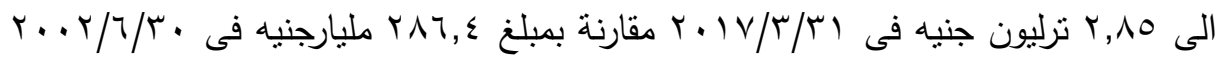
وفقا لبيان البنك المركزى مما يمثل عبئأ على الجهاز المصرفى ما لم يوجه هذة المدخرات

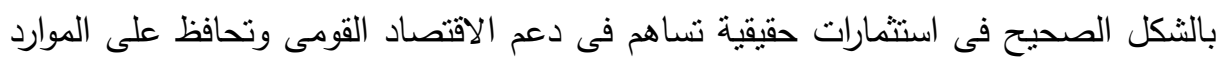

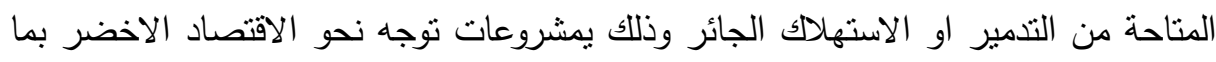
يحقق لها دورها التتموى فى الاقتصاد الوطنى من خلال زيادة حجم الناتج القومى وتتشغيل

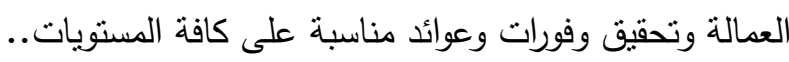




\section{أهساهي الصوراسة}

في ضوء مشكلة الاراسة وما أسفرت عنه الدراسات السابقة من نتائج تسعي الدراسة نحو

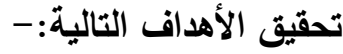

ا-قياس مدى مساهمة القطاع المصرفى لتوجيه مدخرات العملاء للإئمان المصرفى لقطاعات النشاط الاقتصادى فى كلٍ من جمهورية مصر العربية ودولة الامارات العربية المتحدة وسبل زيادة هذة المساهمة r-قياس وسائل دعم القطاع المصرفى للتوجه نحو الاقتصاد الاخضر من خلاد ابتكار وسائل جديدة تؤدى الى توجيه مدخرات العملاء (التى يعانى القطاع المصرفى من تكدسها لديه ) لتوجيها الى شتى قطاعات الاقتصاد الاخضر مما يحقق مجموعة من المزايا والوفورات والاستفادة لكافة قطاعات المجتمع. ب-تحديد وسائل الحفاظ على الموارد المتاحة لدى المجتمع لتحقيق التتمية المستدامة لكافة موارد المجتمع مع التوجه للاقتصاد الاخضر بإعتباره من اهم الوسائل التى تؤدى الى لى لئي

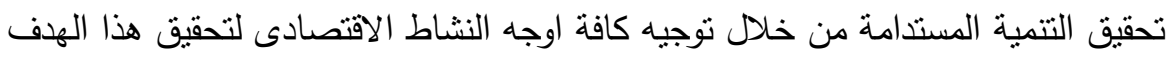
وفقا لتقرير الامم المتحدة عن مصرومحاولة تحقيق الوفورات التى حددها التقرير والتى

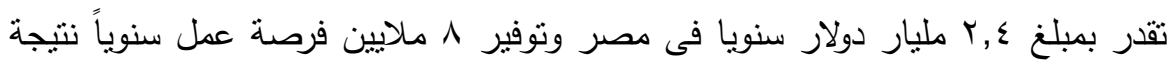
التوجه للاقتصاد الاخضر - الخم ع- الخروج بمجموعة من التوصيات التى قد تفيد فى تحسين حالة الاقتصاد القومى ككل من

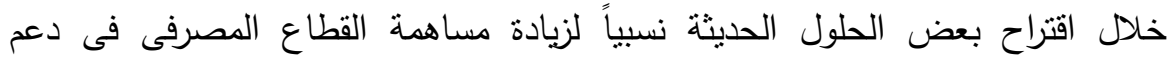

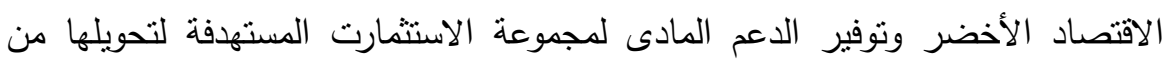

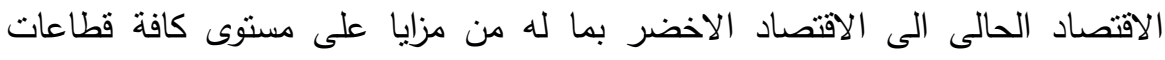

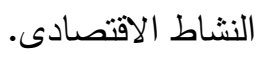




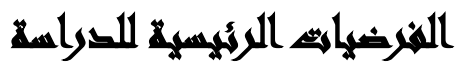

الفرضية الأولي" هناك علاقة بين حجم الدذرات فى الجهاز المصرفى فى جمهورية مصر

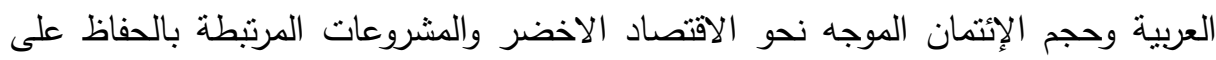
البيئة.

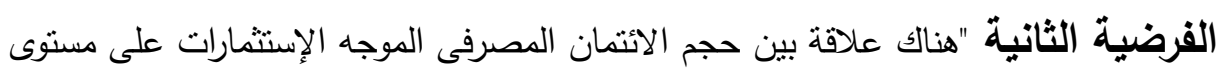

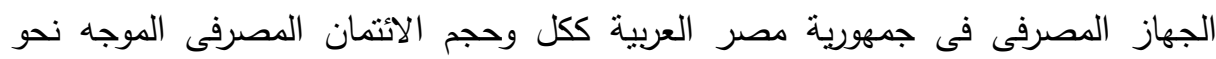
الاقتصاد الاخضر والمشروعات المرتبطة بالحفاظ على البيئة.

\section{حصوض الصواسمة}

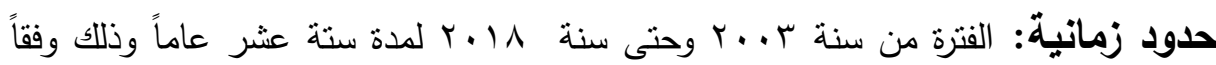
للبيانات المنشورة وهى الفترة النى شهدت نواتراً فى التغيرات الحاكمة لنوجيهات وسياسات

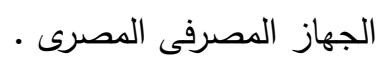
حدود مكانية: سيتم عمل دراسة الجهاز المصرفى فى جمهورية مصر العربية بإعتبارة

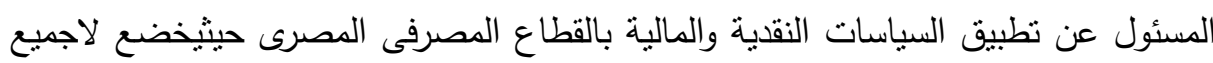
البنوك العاملة فى مصر للإثراف والرقابة من البنك المركزى المصرى.

\section{منهمج التواسمة}

إعتمد الباحث عدة مناهج بحثية في دراسة الجهاز المصرفى ودوره فى دعم التوجه للاقتصاد الاخضر وقد إستخدم الباحث الأسلوبين المكتبي والتحليلى في إعداد دراسته وذلك الكانك

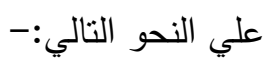

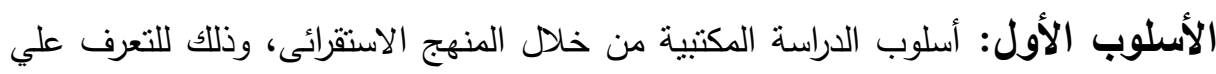

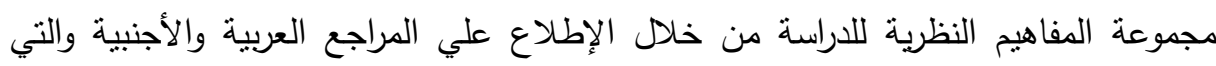

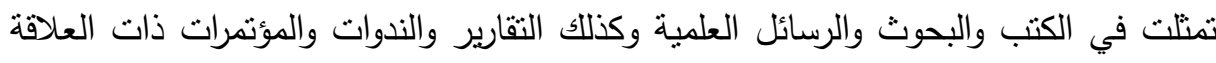
بموضوع الدراسة. 
الأسلوب الثاني: أسلوب الدراسة الاستباطى / التحليلي، وذلك لإثبات صحة أوخطأ فرضيات الدراسة بهذف حل مشكلة الدراسة وتحليل البيانات.

\section{الصراسايت الماريخ}

1- Rabeya Kulsum, S.Sadrul Huda (2018):"Thinking About The Green Banking Model In The Context Of Bangladesh"

$$
\text { هدفت الدراسة الى: - (القاء }
$$

• القاء الضوء على ناثثر تغير المناخ فى بنجلاديش ودور البنوك الخضراء فى مكافحة

• • اظهار السياسات والنماذج المصرفية التى تقدم منتجات مصرفية خضراء.

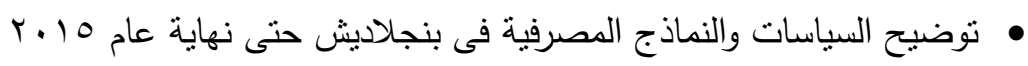

وقد توصلت الدراسة الى مجموعة من النتائج اههها:

• أن غالبية عملاء البنوك والمؤسسات المالية ليس لديهم الوعى الكافى بالاقتصاد الاخضر

وليس لديهم إدراك بأهمية المنتجات المصرفية الخضراء.

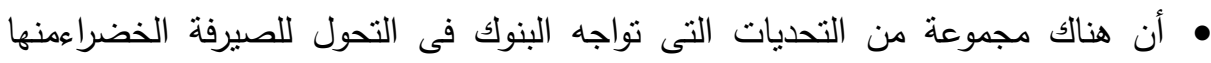

الاقتقار الى الإطار التظظيمى والعملاء المتعثرين.

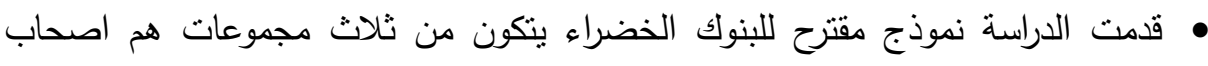

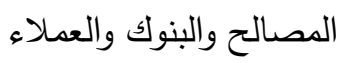

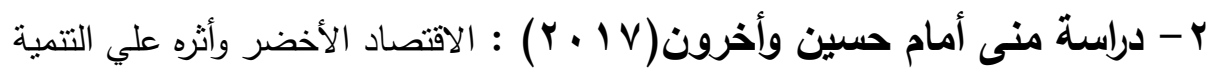
المستدامة في ضوء تجارب بعض الدول، دراسة حالة مصر.

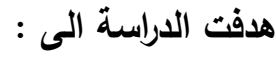

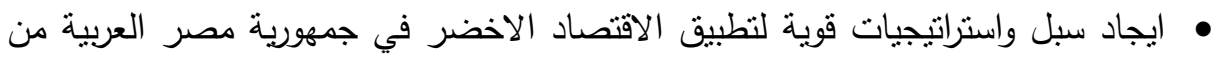
اجل تحقيق تتمية مستدامة وتثجيع الاستثمار وتقليل الفجوة بين الاغنياء والفقراء من اجل الاتل 
• المقارنة ودراسات الحالة لدول تتثابه مع مصر في الظروف والحالة الاجتماعية للاستفادة من تجاربهم في التتمية المستدامة . • لتوضيح افضل السبل التي تساعد للوصول الي التتمية المستدامة باستخدام (الاقتصاد

توصلت الاراسة الى مجموعة نتائج اهمها:

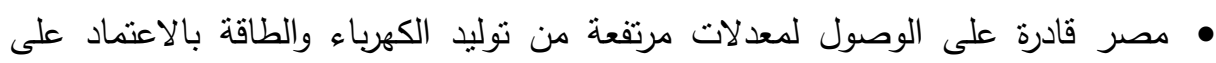

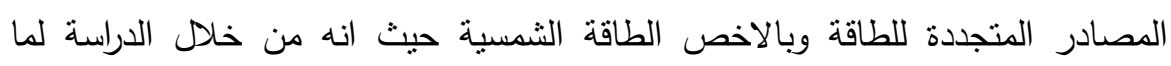
يتوافر لمصر من امكانيات نم التوصل الى انه يمكن نوليد الكهرباء باستخدام الخلايا الفوتوفلطية (نظم الخلايا الثمسية ) منراتيات هالإستتمار الأجنبي كان له دور مباشر و قوي في مجال الطاقة المتجددة في العديد من الدول من أجل تحقيق التتمية المستدامة.

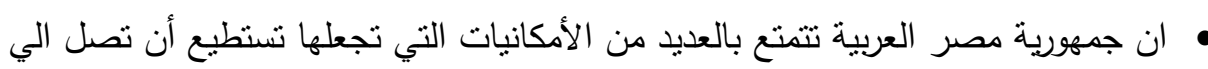

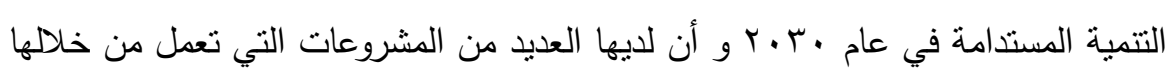
علي تطبيق المنظومة الخضراء و المحاولة الي الوصول للتنمية.

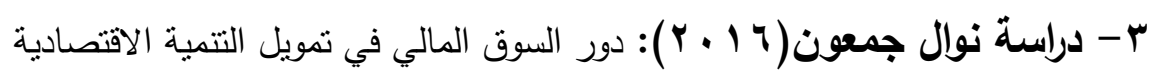
المعوقات والآفاق. هدفت الدراسة الى نتخيص المعوقات التي حالت دون أداء البورصة في الجزائر للدور الذي

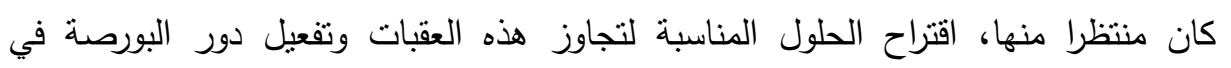
الاقتصاد الجزائري. وتوصلت الدراسة الى الىزئري • ان الواقع الذي تعيثه البورصة في الجزائر إنما هو نتاج لعديد من المعوقات سواء كانت

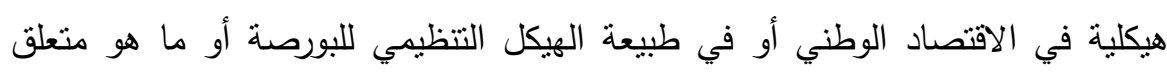

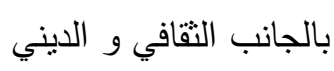
يجب أن يحظى هذا السوق المالى بكثير من الاهتمام. 
4- Yao Wang and Qiang Zhi, (2016): " The role of green finance in environmental protection, Two aspects of market mechanism and policies"

$$
\text { هدفت الاراسة الىى: - (لماء }
$$

• القاء الضوء على دور التمويل الأخضر في حماية البيئة من جانبان من آلية السوق

$$
\text { والسياسات }
$$

• تقييم للوضع الراهن للتمويل الأخضر في مجال الطاقة المتجدة ومعرفة بعض أوجه

$$
\text { القصور. }
$$

• تكريس الاهتمام بنطوير آلية السوق وصياغة السياسات من خلال الكثف عن التناقضات

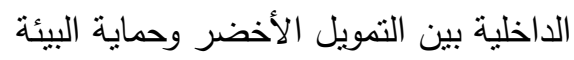

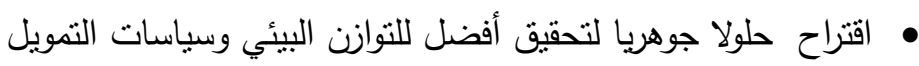

توصلت الاراسة الى : الى جرهيا

• يجب أن يكون لمشروعات حماية البيئة الخاصة تمويل فريد من نوعه يمتل خليطاً بين

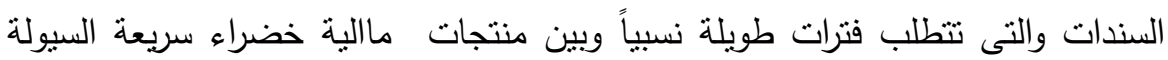
مثل توريق الأصول، لتغيير هيكل لتوفير السيولة اللازمة ولتثجيع المستثمرين على فلى

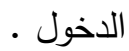
• يجب أن تعمل السياسات على تحسين نشاط سوق التمويل الأخضر من خلال تطويرها

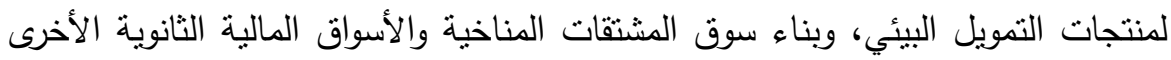

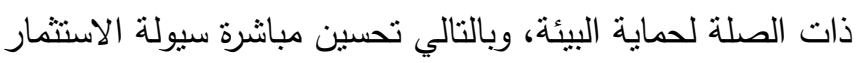

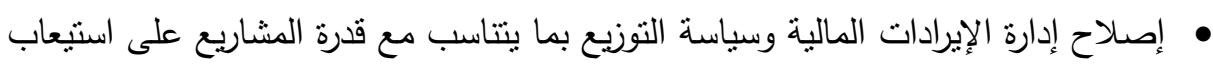

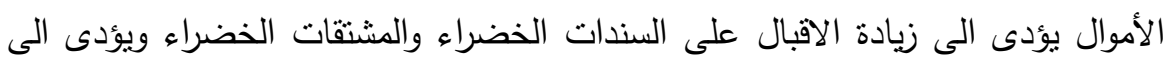

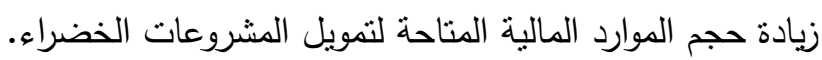

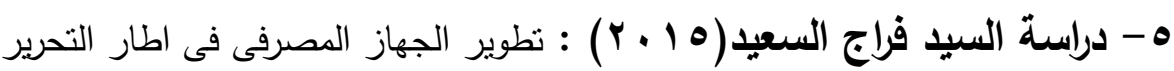
الاقتصادى لدعم لاستقرار والتتمية.

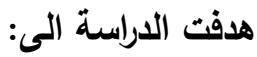


• تحليل وتقييم تجربة التحرير المالى والمصرفى فى مصر وما افرزته من آثار طالت الاستقرار والتتمية • تتاول الأفكار النظرية للتحرير الإقتصادى والمصرفى والسياسات المرتبطة به

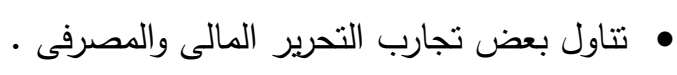

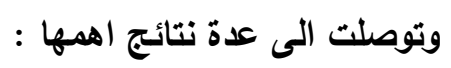

• ان البلدان التى طبقت بعمق التحرير المالى والمصرفى هـى التى التى تعرضت لأزمات مالية ومصرفية حادة ومتكررة • ان الجهاز المصرفى المصرى قد خضع بشكل تدريجى للتحرير •

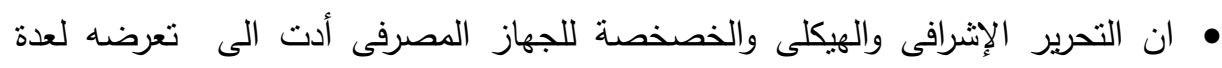
أزمات امتدت من نهاية الألفية الثانية حتى الآن.

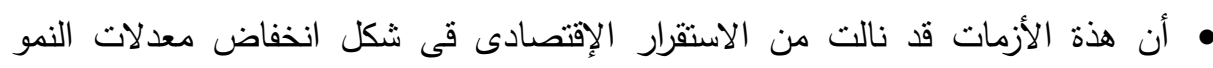
الاقتصادى، ارتفاع معدلات البطالة، تتامى عجز ميزان المدفوعات.

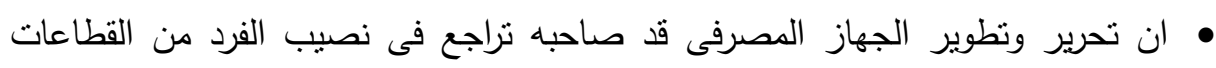
السلعية من الإيتمان المصرفى ومن ارصدة الاقراض والخصم.

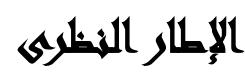

المههمه الاول: مقدمة: ظهر الاقتصاد الأخضر استجابة لأزمات متعددة، ويهدف الى تحقيق تنمية اقتصادية عن طريق مشاريع صديقة للبيئة وباستخدام تكنولوجيات جديدة في مجال الطاقات المتجددة والنظيفة، ويدعو إلى خضرنة القطاعات القائمة وتغيير أنماط

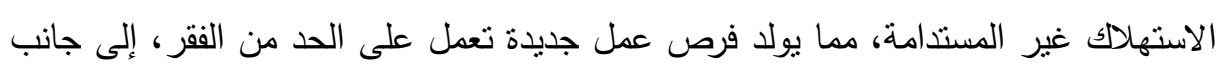

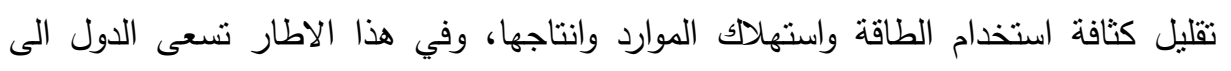

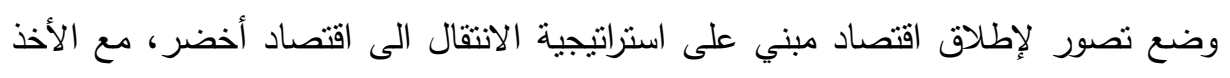

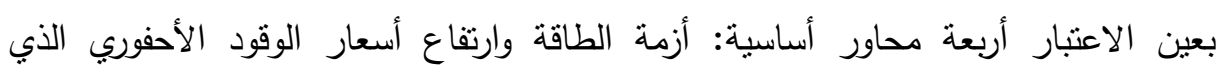

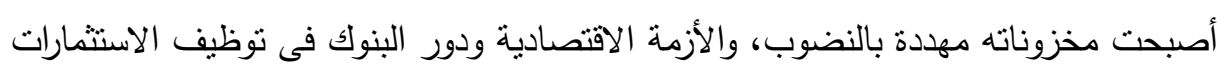

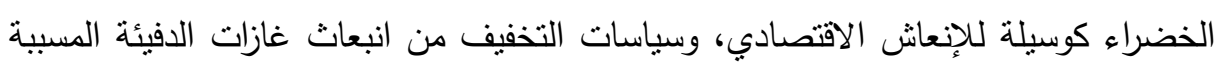
446

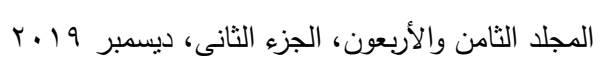


للاحتباس الحراري، والقناعة القوية لبعض الدول بضرورة وضع نموذج جديد للتنمية المستدامة

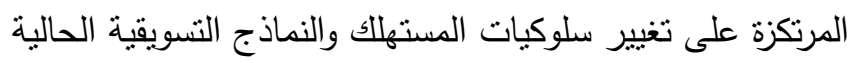

يعرف برنامج الأمم المتحدة للبيئة يعرف بأنه " هو ذللك الأقتصاد الذي ينتج فيه تحسن

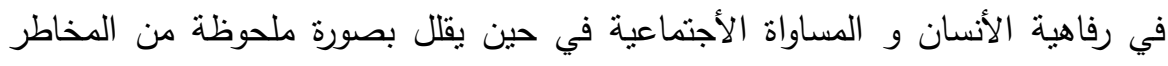

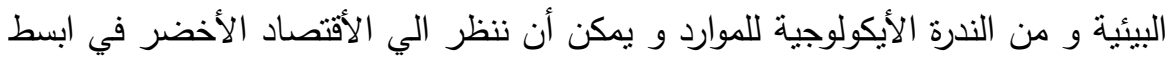

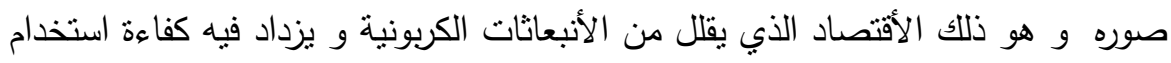

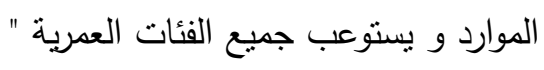

• يعرف Chapple ( الاقتصاد الأخضر على أنه افتصاد الطاقة النظيفة، يتكون أساسا من أربعة قطاعات: الطاقة المتجددة منل (الطاقة الثمسية وطاقة الرياح والطاقة الحرارية الأرضية)؛ المباني الخضراء ،والنقل؛ وإعادة التدوير وتحويل النفايات إلى طاقة. و الاقتصاد الأخضر لا يقتصر فقط على القدرة على إنتاج الطاقة النظيفة، ولكن أيضا

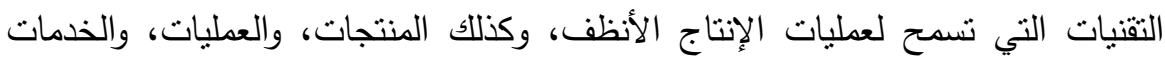
التي تقلل من الأثر البيئي أو تحسين استخدام الموارد الطبيعية.

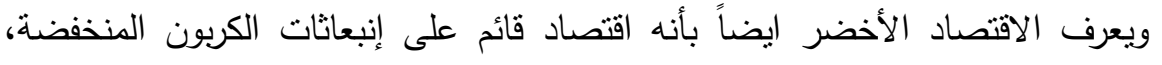

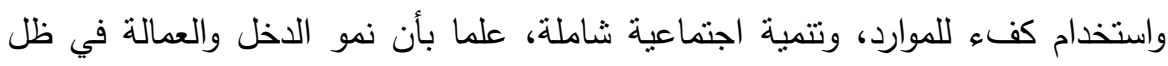

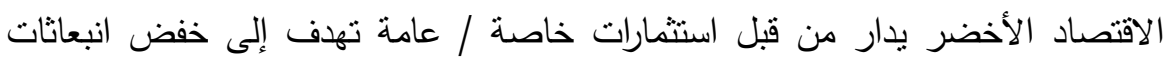

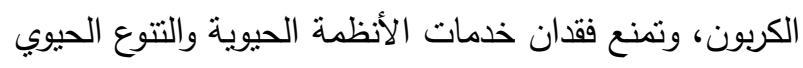

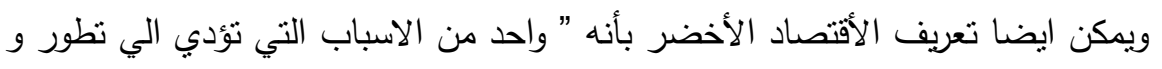

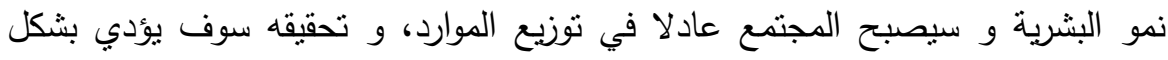
ملحوظ الي تقليل الأخطار و الندرة البيئية " 
همكن للباحث تعريف الإقتصاد الأخضر بأنه"هو أحد النماذج الجديدة للتتمية الأقتصادية

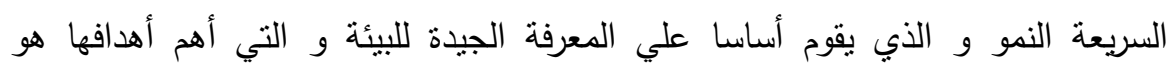

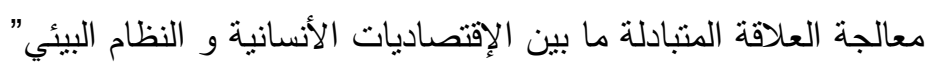
r- حافز الأنتقال و التحول الي الأقتصاد الأخضر:

تخفيف حدة الفقر وخصوصاً فى المناطق الريفية:.

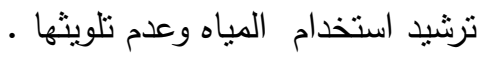
خفض دعم أسعار الطاقة و دعم قطاع النقل الجماعي. • التصدي لمشكلة النفايات الصلبة و محاولة أعادة ندويرها. زيادة الأستثمارات المستدامة في مجال الطاقة و أجراءات رفع كفاءة الطاقة.

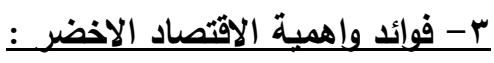
الاقتصاد الاخضر محوري لازالة الفقر .

الاقتصاد الأخضر يخلق فرص العمل ويدعم المساواة الاجتماعية .

الاقتصاد الأخضر بستبدل الوقود الأحفوري بالطاقة المستدامة والتقنيات منذفضة

$$
\text { • الكربون. }
$$

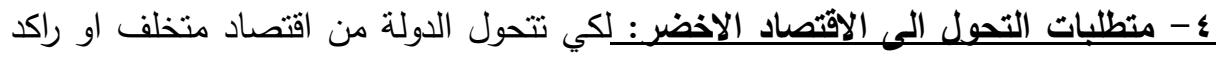

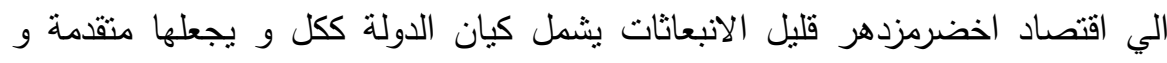

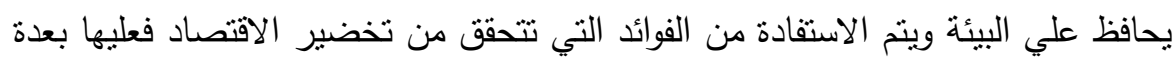

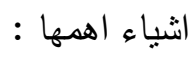
• ان تقوم الدولة بتتمية الريف عن طريق الاهتمام بالزراعة والهحافظة علي الغابات

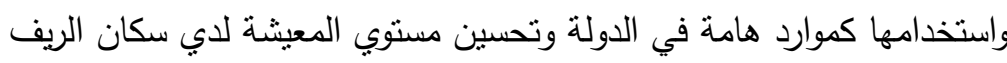

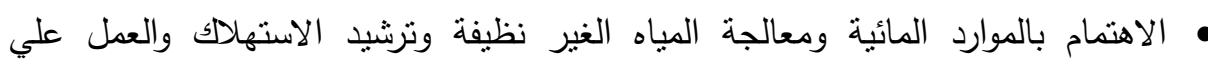

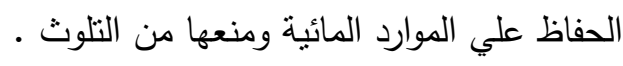


مراجعة السياسات الحكومية وجعلها سياسات خاضعة لنظام الاقتصاد الاخضر فاذا كانت

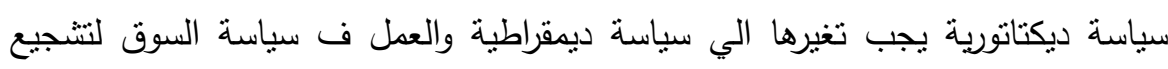
الانتاج

• علي الاقتصاد الاخضر ان يعترف بالسياسة الوطنية علي الموارد الطبيعية وان بركز علي

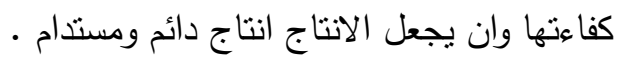
عدم فرض قيود علي التجارة الدولية وعلي الاقتصاد الاخضر ومعالجة التشوهات التجارية

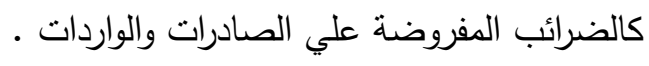
ان تقوم الدولة بالتصدي لمشكلة النفايات والعمل علي معالجنها واعادة تصنيعها مرة

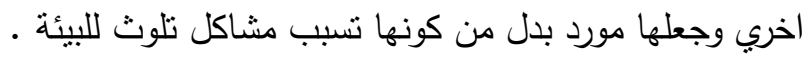

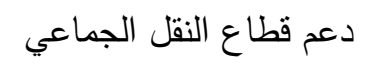
تحسين التعليم ونتجيع الابتكار . تصفي تحفيز مشاركة القطاع الخاص للقطاع العام قى تقديم المنتجات الخضراء الخراء. ه- المنتجات المرتبطة بالاقتصاد الأخضر:

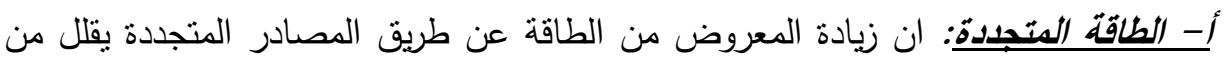
مخاطر اسعار الوقود الاحفورى المرتفعة وغير المستقرة بالاضافة الى تخفيف اثار تغير

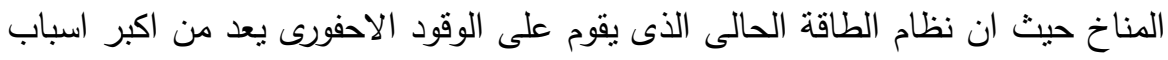

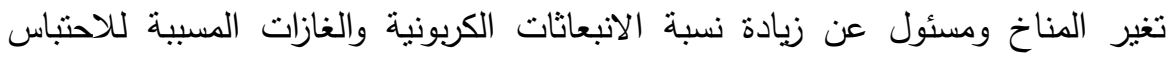
الحرارى، وان الطاقة المتجدة تمنل فرصة اقتصادية رئيسية، ويتطلب هذا القطاع استبدال الاستثمارات في مصادر الطاقة المعتمدة بثده على الكربون باستثمارات فى الطاقة

ب- الأنية الخضراء: يتطلب التحول الى اقتصاد اخضر التركيز على العمارة الخضراء والتى مانى

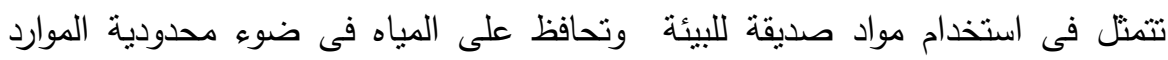
المائية، وتقلل من استهلاك الطاقة الكهربائية رغم زياده الطلب عليها، وذلك لتقليص الانبعاثات التى تغير فى المناخ، ويعتبر التحول الاخضر لقطاع البناء قضية اقتصادية

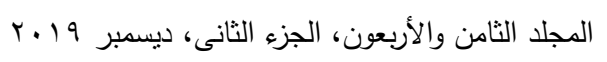


واجتماعية مهمة من حيث انثاء وظائف وصناعات جديدة، وسيكون لهذا البناء ناثير بعيد

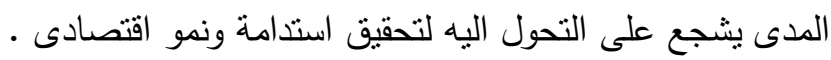

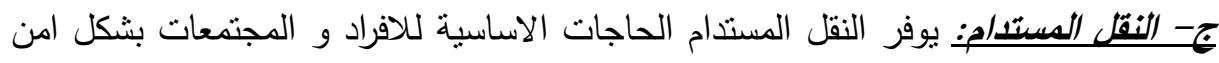

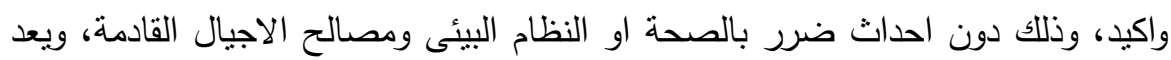

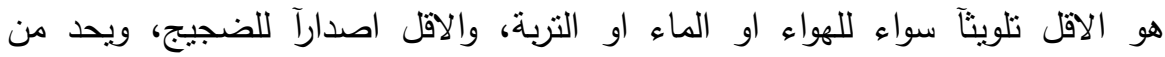
الانبعاثات الدفيئة، وبالتالى لا يؤثر بالسلب على المناخ او الاحترار، وذلك لان وساء ولهائل النقل فيه تكون معتمدة على مصادر الطاقة المتجددة، والسيارات و النقل العام تعمل جزئياً على الكهرباء .

لد- إدارة المباه المستد/مة: تعد المياه عنصرآ جوهرياً من عناصر التتمية، وان للنظم الايكولوجية دورآ رئيساً فى الحفاظ على المياه كمآ ونوعآ، وان ادارة المياه ترنبط بالرى وتوفر مياه الثرب والصحة والمرافق الصحية، ونتير التقديرات الى ان نحو نصف الى تلى

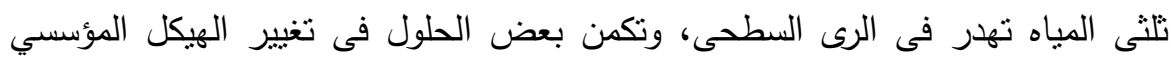

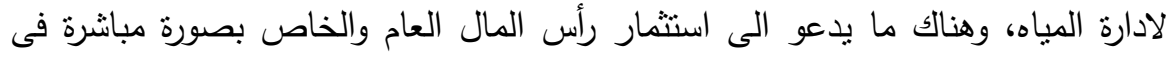

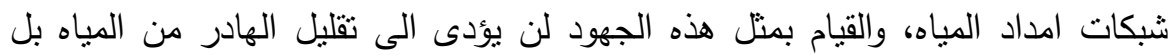
ينطوى ايضا على انه سيوفر فرص العمل المنخفضة لمتوسط المهارات، فسيعمل الاقتصاد الاخضر على جمع مياه الامطار واعاده استخدامها، وتحليه مياه البحار، وتوليد طاقة من المياه، وايضا اعاده استخدام المياه المستخدمة وذلك رغباً في الحفاظ على المخزون الإناه المائي.

هـ - إدرة المخلقات: وهى عباره عن اعادة تدوير المخلفات لانتاج منتجات اخرى اقل جودة

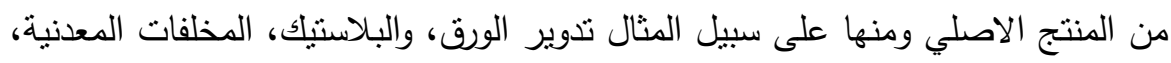
الزجاج، وكذلك اعادة تدوير المخلفات الحيوية عن طريق المعالجة بالتخمر الهوائي

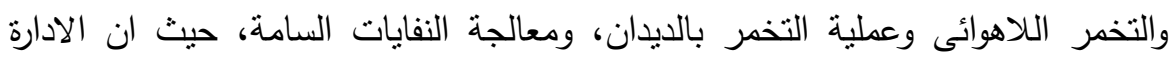
الخضراء للمخلفات تعمل على انثاء وظائف وتوفير فرص استثمارية فريدة فى اعادة التدوير وانتاج السماد العضوى وتوليد الطاقة، حيث ينم الاستفادة من المخلفات الزراعية التى هى منتجات ثانوية داخل منظومة الانتاج الزراعى عبر تحويلها الى اسمدة عضوية 
او اعلاف او غذاء للحيوان او طاقة نظيفة او تصنيعها فيما يضمن تحقيق زراعة نظيفة وحماية البيئة من التلوث وتحسين الوضع الاقتصادى والبيئي ورفع المستوى الصحى

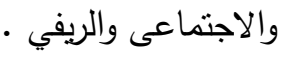

و- إدارة الأرلضح (النزاعة المستد/مة) : لابد من من الاهتمام بمفهوم الاقتصاد الاخضر

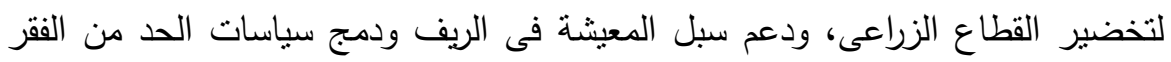

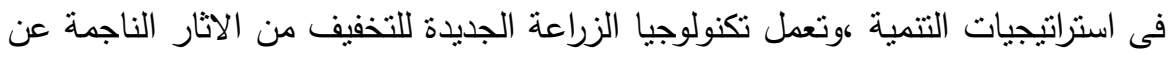
تغير المناخ، وتعزيز شراكات التتمية، لمواجة التحديات البيئية المعاصرة كالتصحر ، وازالة

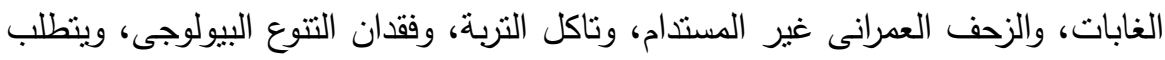
ذللك تكوين فهم مشترك للنمو الاخضر وتطوير نموذج نظرى بشان ذللك، فضلا عن تطوير مجموعة من المؤشرات التى تغطى الجوانب الاقتصادية و البيئية والرفاهية

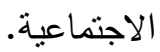

צ- الاقتصاد الاخضر والتوظف: أدى التحول إلى اقتصاد مستدام بيئياً إلى ظهور الوظائف

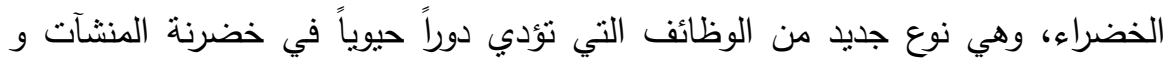
المجتمعات f- مفهوم الوظائف الخضراع: تعرف الوظائف الخضراء على أنها تلك التي تقدم المنتجات

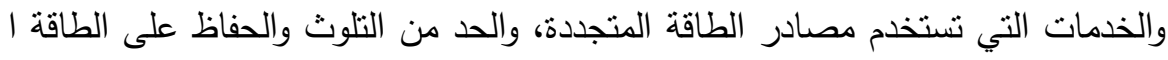
ولم وارد الطبيعية، وإعادة النفايات. وتثنمل إزالة السموم من البيئة، وإعادة تجهيز المباني

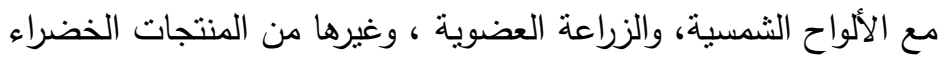
ب-أهمبة الوظائف الخضراع:

الوظائف الخضراء وسيلة لجذب الناس من المجتمعات الفقيرة إلى العمل من خلال تدريبهر على المهارات لإنتاج المنتجات أو الخدمات الصديقة للبيئة. هالوظائف الخضراء توفر وسيلة لتوليد العمل اللائق، و في الوقت نفسه تحقيق التتمية الاقتصادية والاجتماعية المستدامة البيئية. 
• الوظائف الخضراء تقلل من الأثر البيئي للمشاريع والقطاعات الاقتصادية، في نهاية المطاف إلى المستويات التي تعتبر مستدامة.

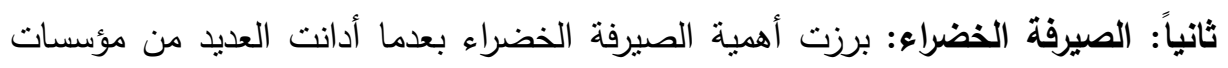

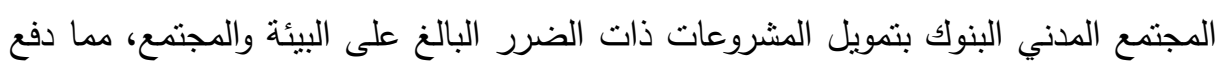

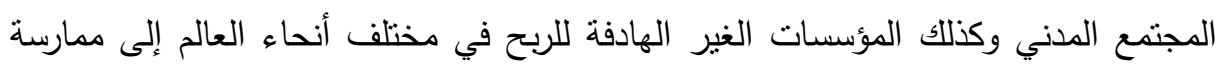

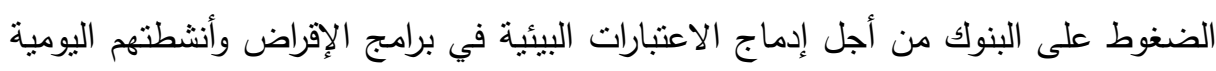

$$
\text { على نحو يؤكد مسئولية المصارف عن أعمالها. }
$$

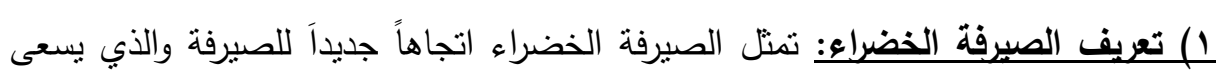
إلى توفير الدعم المالي منخفض التكلفة وطويل الأجل لمشروعات الطاقة النظيفة منخفضه

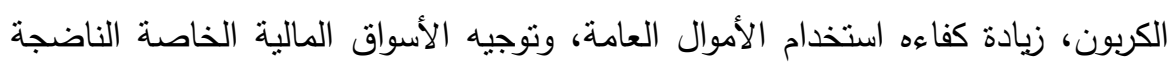
نحو الاستثمار في الطاقة النظيفة. فتعمل الصيرفة الخضراء على تحقيق النمو لكل من النماءه

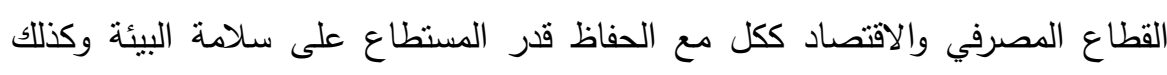

الالتزام بمعايير ترشيد استهلاك الموارد الطبيعية.

r) آليات الصيرفة الخضراء: لقد بدأت العديد من البنوك حول العالم في اتباع منهجية الصبرفة الخضراء وذلك عن طريق تبنى مجموعة متتوعة من المنتجات والأنشطة الجديدة. وفي هذا الإطار بمكن تلخيص آليات الصيرفة الخضراء فيما بلي:

$$
\begin{aligned}
& \text { • تحديث العمليات المصرفية والبنية التحتية. } \\
& \text { • تصميم مجموعة جديدة من المنتجات والخدمات الخضراء. }
\end{aligned}
$$

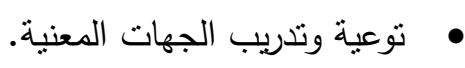

$$
\begin{aligned}
& \text { • تحديث العمليات المصرفية والبنية التحتية . }
\end{aligned}
$$

خلال السنوات القليلة الماضية، اتخذت البنوك عدة تدابير من أجل تقليل انبعاثات

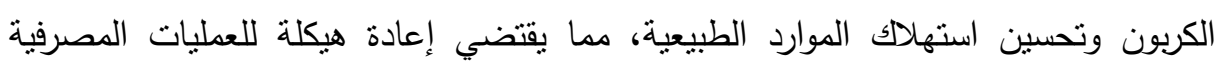
والبنية التحتية للمؤسسات على أسس ومعايير جديدة صديقة للبيئة.

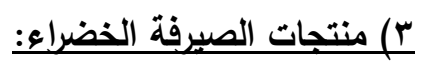


أ- المبانسي الخضراع: يشير مصطلح المباني الخضراء، وتُعرف أيضاً بالأبنية المستدامة، إلى عملية إنثاء مباني صديقة للبيئة واستخدام عمليات ذات كفاءة بيئية عالية في استخدام الموارد طيلة دورة حياة البناء، بدءاً من تحديد الموقع والتصميم والتتغيل والترميم التئه

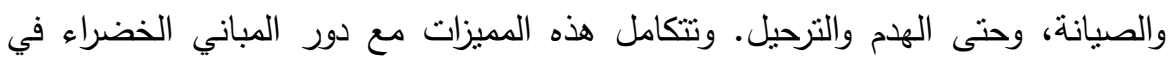

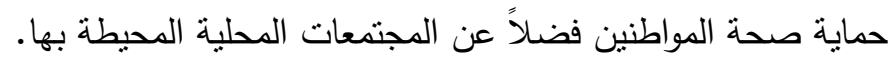

\section{ب- عمليات مصرفية غير وقية:}

• تعزز الصبرفة الخضراء استخدام المعاملات غير الورقية والخدمات المصرفية عبر

$$
\text { الإنترنت (متل خدمات الرسائل القصيرة وماكينات الصراف الألى) }
$$

• تصميم مجموعة جديدة من المنتجات والخدمات الخضراء يتم تصميم مجموعة جديدة من

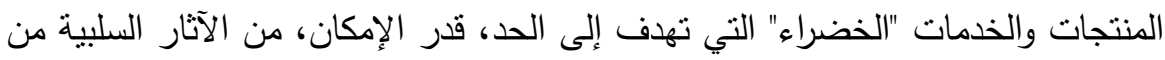
أجل تعزيز التتمية المستدامة. ومن أمتلة المنتجات التي وضعتها البنوك ما يلي: ج- البطاقات الخضراع: تمنل بطاقات الخصم والائمان الخضراء منتج من أهم المنتجات المقدمة لتتجيع وتطوير الصيرفة الخضراء. وهي بطاقات صممت لدعم الأنشطة البيئية من خلال تخصيص نسبة تبرع للمنظمات غير الحكومية نساوى 0 ., • \%من كل عملية مصرفية أدلى بها صاحب البطاقة.

لد-التمويل العقاري الأخضر: ويتضمن قروض منخفضة التكلفة تُّم اللعملاء الذين بعتزمون شراء منزل "ذو الطاقة النظيفة، " مما يؤدى إلى الحد من الواردات والنفايات الورقية ويضمن إتمام المعاملات بشكل أسرع وأكثر أمناً.

هـ- بنية تحتية خضراع: التحول إلى اتجاه الصيرفة الخضراء يقتضي ضرورة وجود بنية

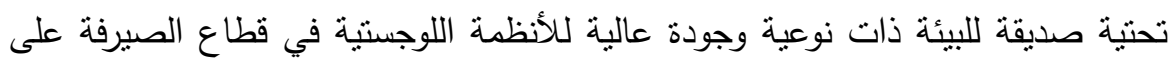
نحو يوفر مجموعة متكاملة من خدمات البنية التحتية التي تعزز استخدام الطاقة النظيفة. فوجود هذه البنية التحتية يضمن تحقيق العناصر الضرورية لبيئة نظيفة وصحية بشكل

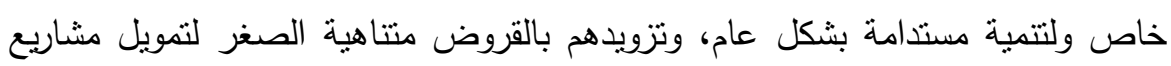
بيئية، مثل منشآت الطاقة الثمسية ومحطات إعادة التدوير . 
و- المنتجات غير الموقية: في إطار تعزيز العمليات المصرفية الغير ورقية، تعمل البنوك

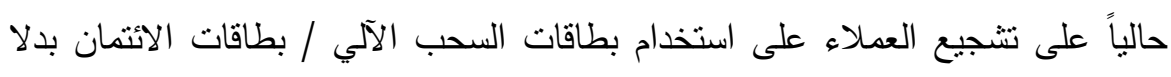

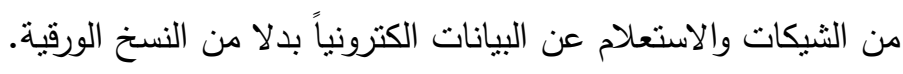

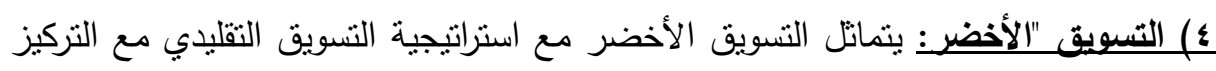

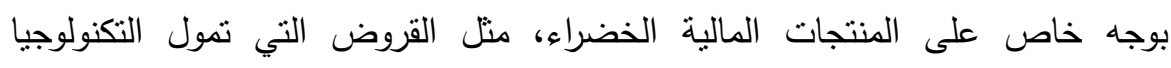

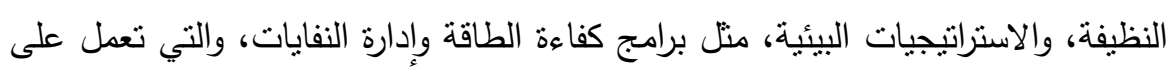
تحسين أداء البنوك البيئي وكذلك كسب الثنة.

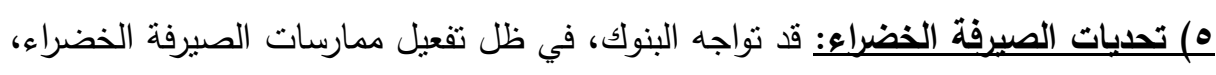
بعض التحديات والأعباء التي يمكن تلخيصها على النحو النالي:

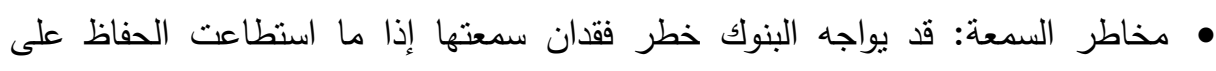
مشاركتها في الاستثمار الأخضر وتمويل المشروعات الصديقة للبيئة. • ت تكاليف النشغيل المرتفعة:

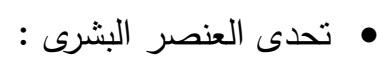

إذ تحتاج البنوك "الخضراء" إلى الموظفين ذو الخبرة والمهارة لضمان تقديم الخدمات

المالية بجودة عالية للعملاء.

\section{المبحث الثانى: دور البنوك فى دعم مشروعات الاقتصاد الاخضر}

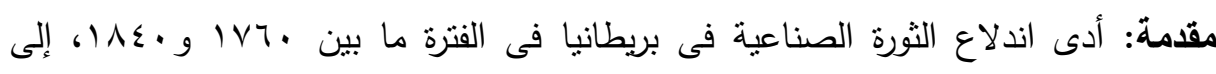

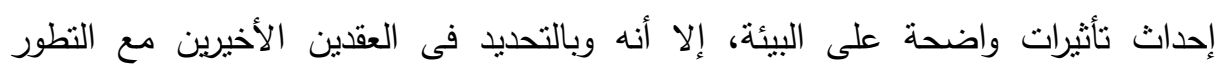

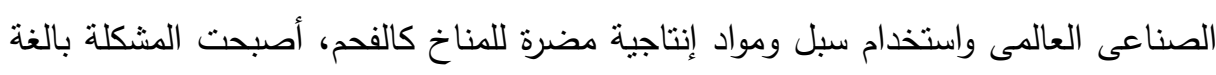
الخطورة على المناخ والبيئة والكائنات الحية أيضاً. لذللك اتجه القطاع المصرفى العالمى إلى تمويل المشروعات صديقة البيئة، والداعمة

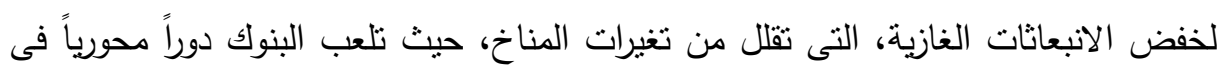

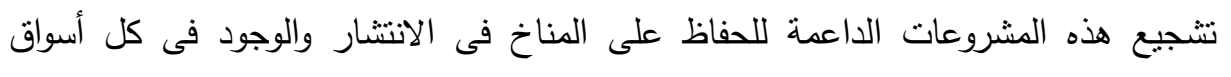

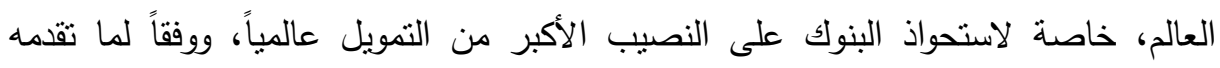


البنوك من شروط ميسرة وفوائد منخفضة تستقطب البنوك المزيد من هذه المشروعات الخضراء.

وفيما يخص القطاع المصرفى المصرى اتجهت البنوك المصرية فى الفترة الأخيرة إلى تتفيذ خطط طموحة تدعم نمو محفظة تمويلات المشروعات الخضراء، والمشروعات الأكثر حفاظاً على المناخ.

أن دعم الصيرفة الخضراء التى تعنى نوفير التمويل لدعم الطاقة النظيفة، وتمويل

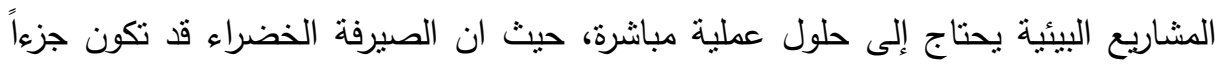
من معايير تقييم البنك المركزى المصرى للبنوك خلال الفترة المقبلة. وفيما يلى اثارة الى الدور الذى نقوم به مجموعة من البنوك الدولية والمحلية

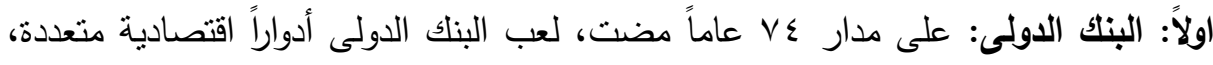

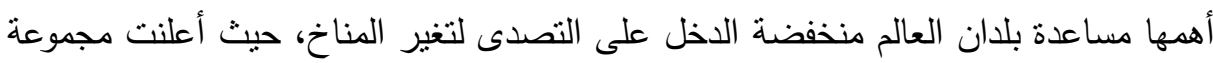

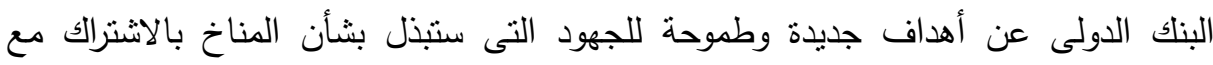

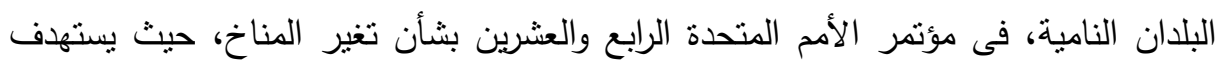

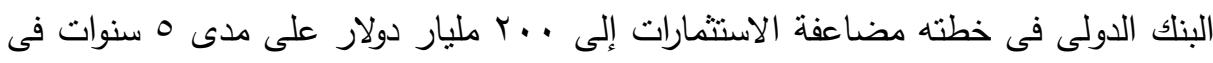

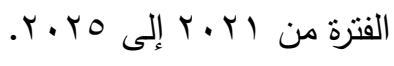
وأنشار البنك الدولى إلى أنه مع التغيرات المكانية التى يسببها المناخ فى الأراضى

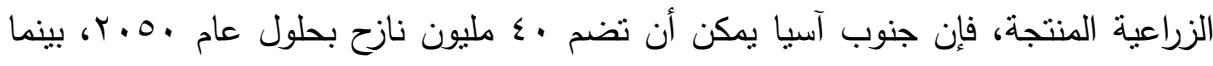

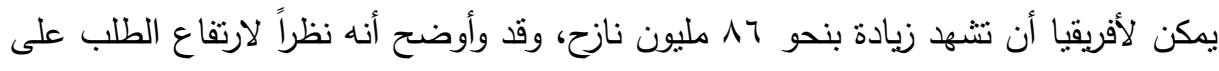
التمويل وضخامته ستكون هناك حاجة إلى نحو تريليون دولار فى البلدان الأثد فقراً، لتلبية

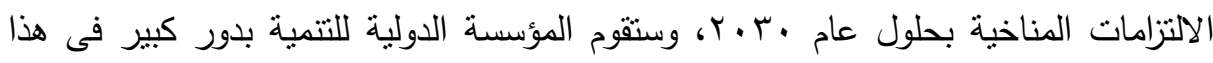

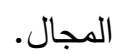
ثانياً: مبادرة البنك الاهلى المصرى: فيما يخص المبادارات الخضراء للبنك الاهلى نذكر منها:

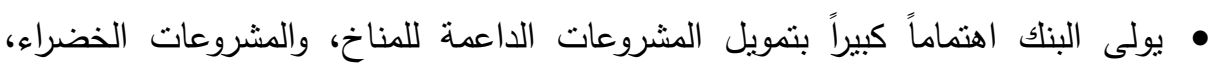
خاصة خلال السنوات الأخيرة. 
• البنك يراعى الالنزام بالمعايير البيئية عند تقديم تمويلات خاصة بالمشروعات الضخمة.

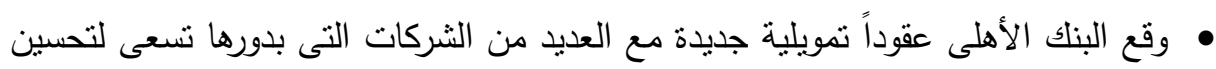

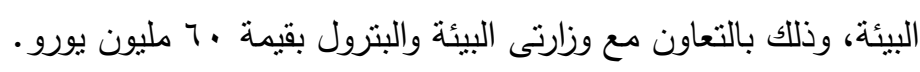

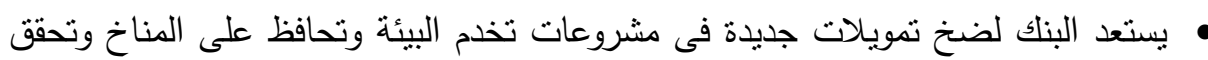
أهداف التنمية المستدامة. • يسعى البنك الأهلى للحصول على جزء من قيمة تمويل البنك الدولى الموجه لهذا القطاع.

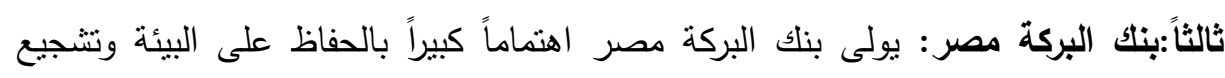

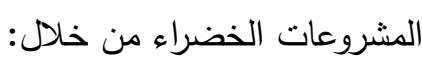
• إعتماد البنك خطة لاستخدام الطاقة الثمسية فى كل المعاملات بشكل كامل خلال السنوات المقبلة.

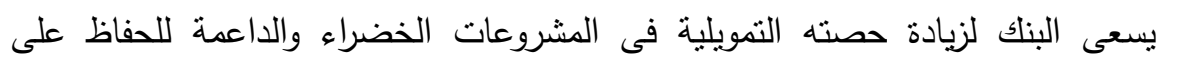

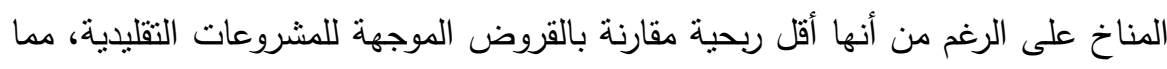
يعكس الدور الاجتماعى الذى تقوم به البنك، ويحافظ على البيئة بشكل كبير .

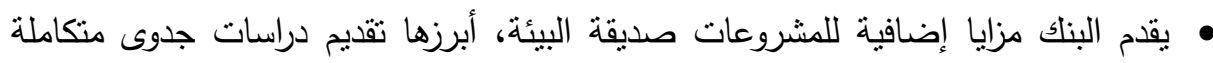
للمشروع، وتقديم الدعم والتدريب الفنى، بالإضافة إلى وضع خطط تسويقية متميزة، وإتمام كل التراخيص اللازمة للمشروع.

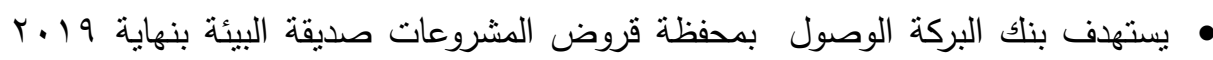

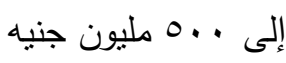

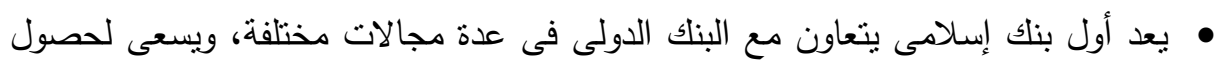

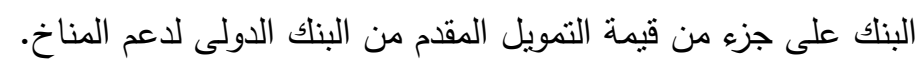

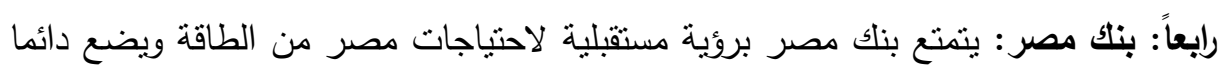
ضمن أولوياته تتفيذ السياسات العامة للاولة في مجال التمويل والتسهيلات الائتمانية ومنها: • وقع بنك مصر و أونيرا لأنظمة الطاقة اتفاق تعاون لتمويل مشروعات الطاقة الجديدة

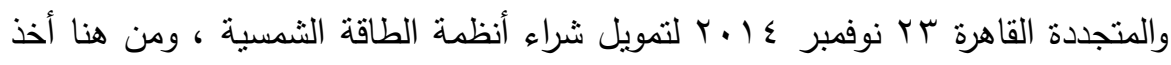

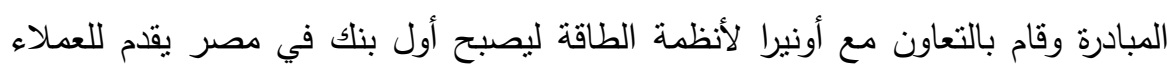


خدمات تمويل برامج الطاقة الجديدة والمتجددة، وخاصة الطاقة الثمسية باعتبار أنها من أكثر الصناعات المرتبطة بالجماهير بما ينعكس إيجابياً على تتجيع ومساندة كافة شرائح المجتمع في كافة منطلباتها،

• رصد بنك مصر مبالغ تمويلية مختلفة لتمويل مشروعات الطاقة الثمسية طبقاً لخطة الدولة في نوليد من با الف الى 10 الف ميجا وات خلال العامين القادمين..

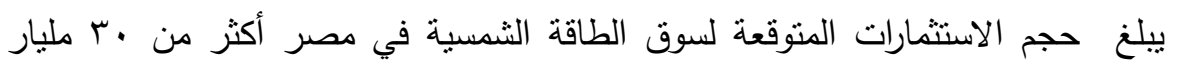

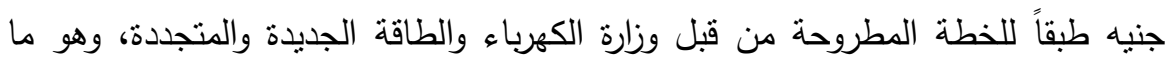
يتطلب إسهامات كبيرة من القطاع المصرفي في مصر". بتفاوض مع البنك الدولى للحصول على جزء من قيمة القرض المقدم بقيمة . . ب مليار دولار خلال الـ سنوات المقبلة. خامساً:البنك العربى الأفريقى الدولى: قام البنك بدعم العديد من المشروعات التى تخدم البيئة : منها • للبنك دور أساسى فى تدريب دفعات على كيفية إنشاء مشروعات تحقق التتمية المستدامة.

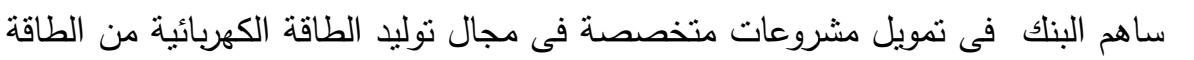

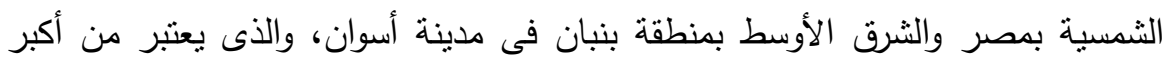

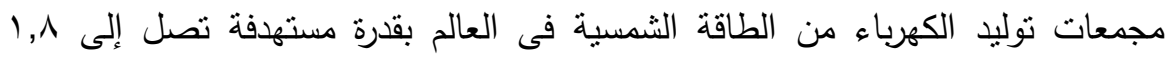
جيجاوات، والذى سيساعد فى زيادة حصة إنتاج وتوليد الكهرباء من الطاقة المتجددة

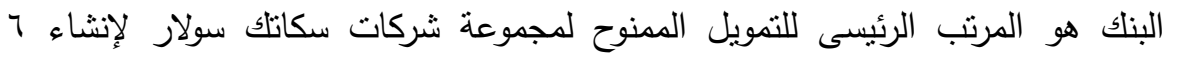
محطات لتوليد الطاقة الكهربائية من الطاقة الثمسية بمنطقة بنبان فى مدينة أسوان بقدرة

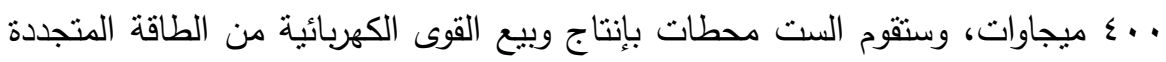

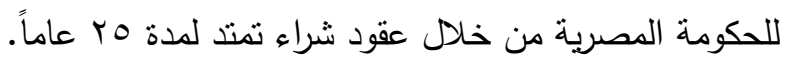

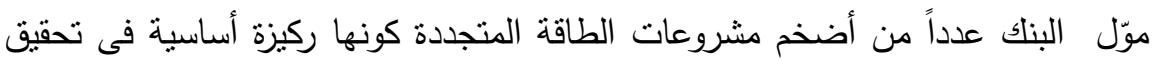
التتمية المستدامة والمشروعات المتعلقة بمجال توليد الطاقة الكهربائية من الطاقة الشمسية

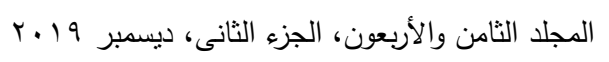


فى مصر ضمن المرحلة الأولى والثانية من مشروعات برنامج تعريفة التغذية التى ترعاها

$$
\text { الحكومة المصرية. }
$$

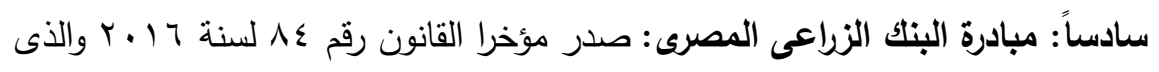

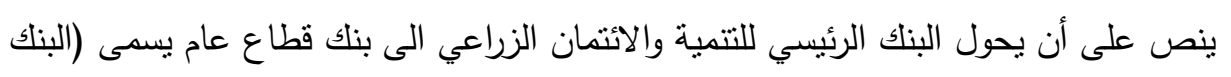

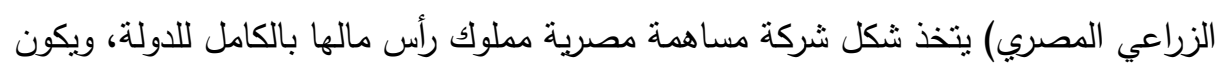

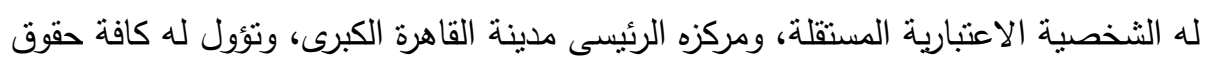

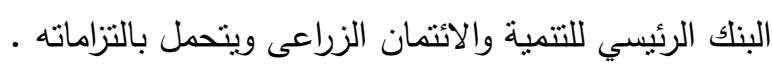

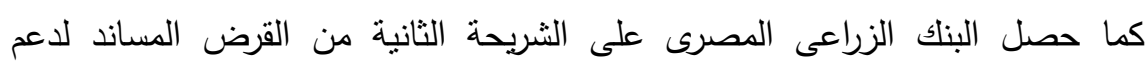

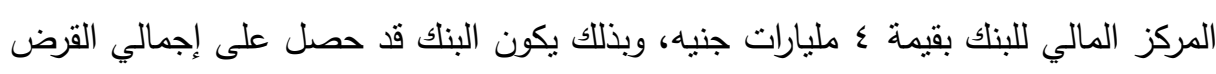
المساند المتفق عليه مع البنك المركزي وقيمته 1,0 مليار جنيه لتدعيم القاعدة الرأسمالية

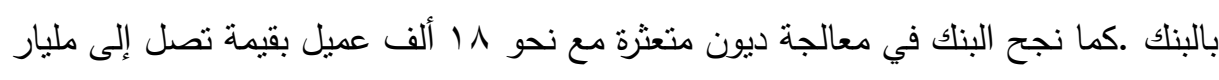

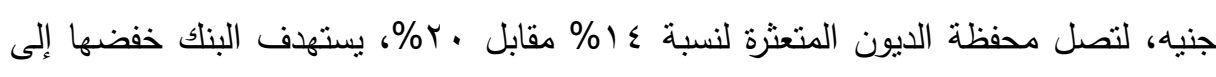

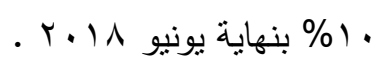
المبحث الثالث: الائتمان الاخضر وعلاقته بالودائع و الائتمان فى الجهاز المصرفى

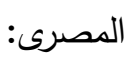
اولاً: العلاقة بين حجم الودائع والائتمان المصرفى والائتمان الأخضر: 
جدول رقم(1) : الودائع والائتمان والائتمان الأخضر والائتمان فى القطاع الزراعى والصناعى فى

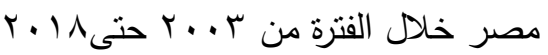

\begin{tabular}{|c|c|c|c|c|c|c|c|}
\hline الصناعى الأنى & الصناعى القيمة & 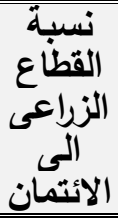 & الزّاعة & الأخضرن & الائتمان & الودائـع & السنة \\
\hline$\cdot$, rOM & 17,701 &.$V$ & ( & 17,99 & $\varepsilon V, 10$ & $7 \neg, \wedge \Gamma \xi$ & $r \ldots r$ \\
\hline$\cdot, \varepsilon r$ & $r \cdot, .09$ & .1 & $\cdot, \Gamma \wedge Y^{\prime}$ & $T_{\cdot, \varepsilon} \varepsilon$ & $\varepsilon \vee, \vee \tau$ & $V \varepsilon, \varepsilon \leqslant r$ & $r \ldots \varepsilon$ \\
\hline$\cdot, \leqslant\rceil 0$ & $r \xi, V R \mu$ & .9 & $\cdot, \Sigma \vee \wedge \vee$ & $Y 0, Y)$ & or, 19 & $\wedge q, \uparrow \wedge \vee$ & r... \\
\hline$\cdot, \varepsilon \leqslant \leqslant T$ & $r \xi, \wedge 0$ & $1, \Lambda$ & $1, \ldots T V$ & YO,AT & 00,94 & $9 \wedge, 1 \vee V$ & $r \ldots r$ \\
\hline$\cdot, \Gamma \wedge$ & YT, Oq & 1,7 & $\cdot, 994 \xi$ & $r \xi, 0 q$ & $7 Y, \cdot 9$ & $11 \varepsilon, .9$ & $r \ldots V$ \\
\hline$\cdot, \Gamma 09$ & $r V, \cdot T r$ & $1, V$ & $1, Y \wedge \cdot 1$ & $r \cdot, 19$ & $V 0, r$ & $1 \leqslant \cdot, 17$ & $r \ldots \lambda$ \\
\hline$\cdot, \Gamma \backslash V$ & $\langle 7, \vee q 1$ & $1, \varepsilon$ & $1, \cdot Y r$ & $r V, \Lambda I$ & $V r$ & $1 \leqslant \varepsilon, 79$ & $r \ldots q$ \\
\hline$\cdot, \Gamma 79$ & $r V, \varepsilon \wedge r$ & 1,9 & $1,\{101$ & $r \wedge, q$ & $V \varepsilon, \varepsilon \wedge$ & $1 \leqslant 9,0 Y$ & $r . r^{\prime}$ \\
\hline$\cdot, \Gamma \div \Lambda$ & $r V, \varepsilon q V$ & $1, r$ & $\cdot, \wedge 977$ & $r \wedge, r_{q}$ & $V \varepsilon, V Y$ & $10 V, 97$ & $r . \mid 1$ \\
\hline$\cdot, r V Y$ & $r O, V O V$ & 1,1 & $\cdot, \vee \vee T / 7$ & YY,OY & $79, Y \leqslant$ & $1 \leqslant 7, \cdot r$ & $T . / T$ \\
\hline$\cdot, \Gamma \wedge \wedge$ & $r q, \wedge \leq 0$ & 1,1 & $\cdot, \wedge \leqslant 7)$ & $r \cdot, 79$ & $V 7,9 Y$ & $177, Y \leqslant$ & $r . \| r$ \\
\hline$\cdot, \Gamma \wedge \varepsilon$ & $r q, q \vee q$ & $1, r$ & $\cdot, 9471$ & $r \cdot, q r$ & $\vee \wedge, \cdot \vee$ & $1 \wedge 9, \wedge \Gamma$ & $r \cdot I \varepsilon$ \\
\hline 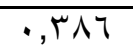 & $Y 7,7 \cdot V$ & 1,1 & $\cdot, V O \wedge Y$ & $Y V, Y \tau$ & $7 \wedge, q \mu$ & $17 r, \wedge q$ & $r .10$ \\
\hline$\cdot, Y \backslash \varepsilon$ & $1 V, 009$ &.$\wedge$ & $0, \Gamma Y \cdot \Lambda$ & $r Y, \Lambda I$ & 77,01 & $1 \cdot r, 1$ & $r .17$ \\
\hline$\cdot, \varepsilon \backslash$ & $r 9,90 \leqslant$ & 1 & $\cdot, \vee \backslash Y \wedge \wedge$ & r., & $\checkmark Y, \wedge \wedge$ & 101,71 & $r . I V$ \\
\hline$\cdot, \Gamma q \varepsilon$ & $\Gamma 0, \wedge q \mu$ & $1, Y$ & $1, .9 \mu r$ & $r 7,99$ & 91,1 & 191,77 & $r \cdot 1 \wedge$ \\
\hline
\end{tabular}

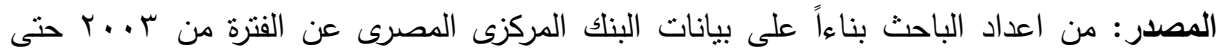


شكل رقم(1): الائتمان والايتمان الأخضر والائتمان فى القطاع الزراعى والصناعى فى مصر

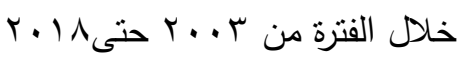

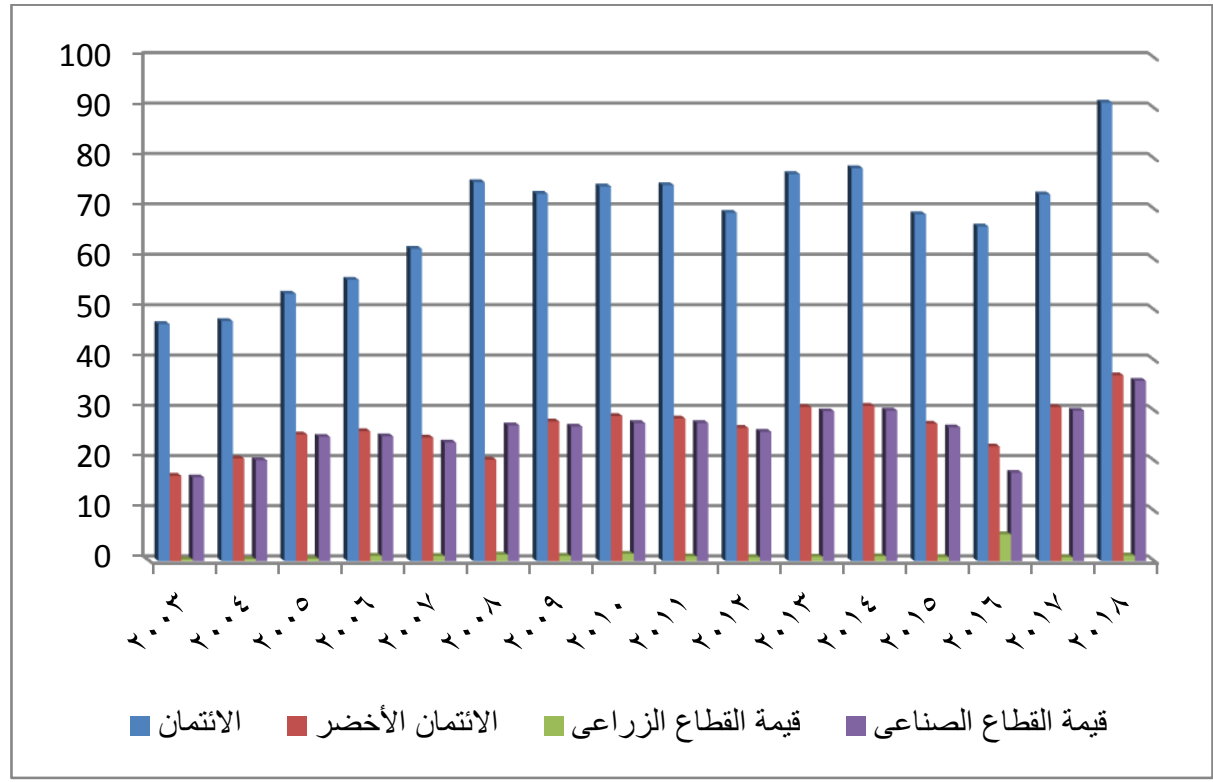

المصدر: من اعداد الباحث بناءاً على بيانات البنك المركزى المصرى عن الفترة من r... حتى

يتضح من الجدول و الثكل السابقين ان حجم الائنمان الاخضر يتمنل فى قطاعين

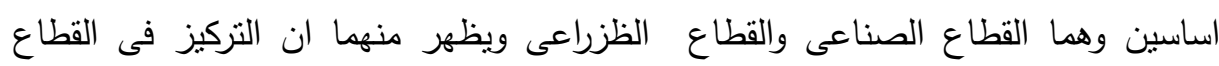

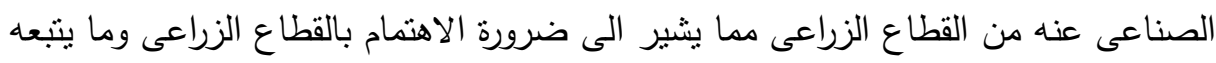

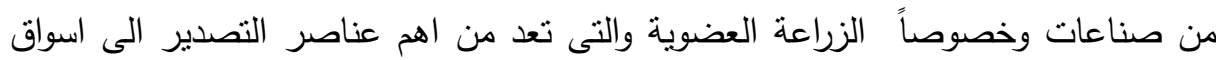

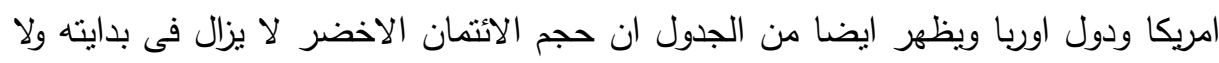
بد من ابتكار انواع جديدة من منتجات الصيرفة الخضراء تؤدى الى زيادة حجم الائتمان

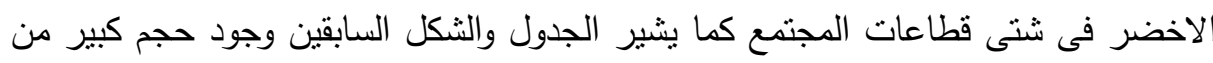
الودائع غير مسغل وانخفاض نسبة التوظيف مما يدعو الى الاهتمام بالصيرفة الخضراء لتوظيف الفائض من اموال الودائع فى مجالات خضراء تؤدى الى زيادة نسبة نوظيف الودائع وزيادة فرص التوظيف وتفتح المجال الى المزيد من الرفاهية وتخفيض معدلات الفقر وتحقيق 
العدالة الاجتماعية وتزيد من معدلات لنمو الاقتصادى فى العديد من المجالات مع المحافظة

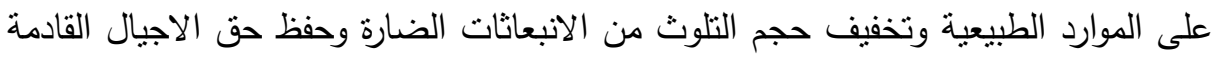
من حقوقهم من الموارد المتاحة.

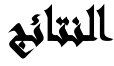 \\ نتائج الدراسة من حيث إثبات صحة أو خطأ الفرضيات:-}

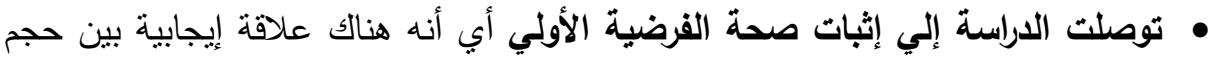

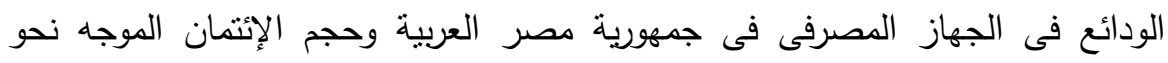

الاقتصاد الاخضر والمشروعات المرتبطة بالحفاظ على البيئة.

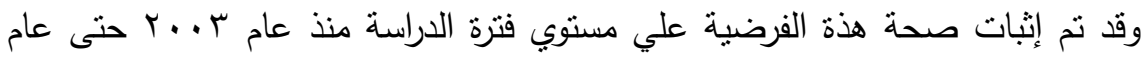

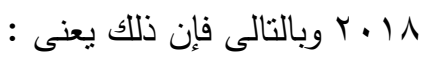

انه على الرغم من تكس الودائع بالجهاز المصرفى المصرى الا أن هناك علاقة ايجابية بين حجم الودائع وبين حجم الائتمان المصرفى الموجه نحوالمشروعات الخضراء الا أن نسبة

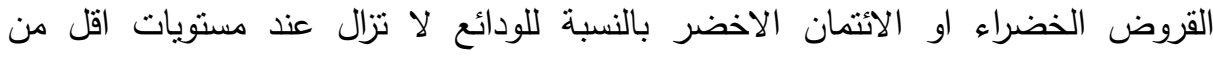

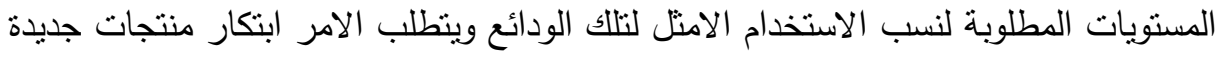
على السوق المصرى منل السندات الخضراء وصناديق الاستثمار الخضراء تكون مخصصة

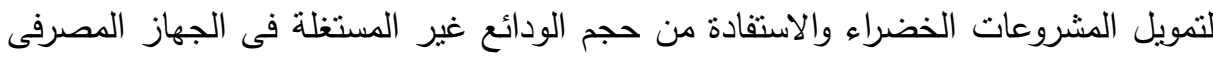

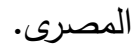

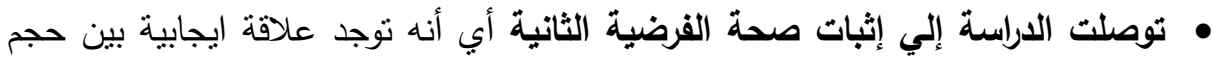

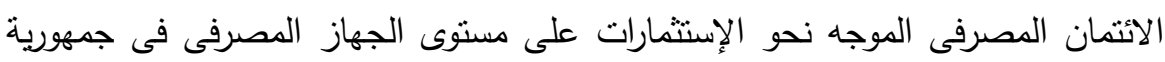
مصرالعربية ككل وحجم الائتمان المصرفى الموجه نحو الاقتصاد الاخضر والمشروعات المرتبطة بالحفاظ على البيئة.

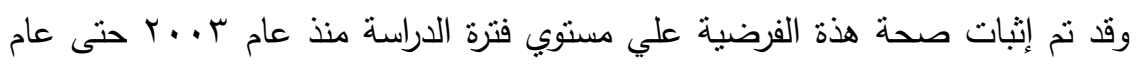

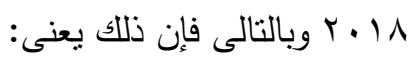


بلغ حجم التسهيلات الائمانية فى الجهاز المصرفى المصرى معدلات متزايدة خلال فترة

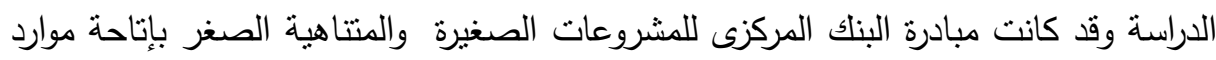

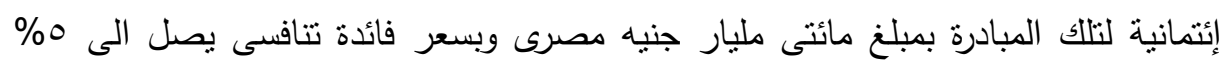

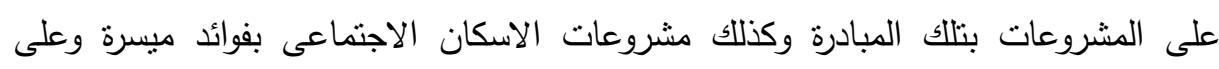

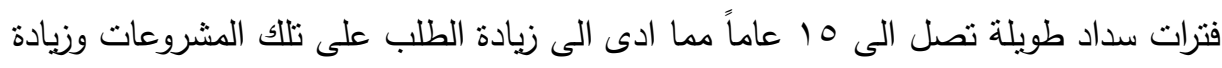
حجم الاثتمان على مستوى الجهاز المصرفى المصرى ككل ولكن ينقص تلك المبادرة انتشترط ان يكون التمويل للمشروعات الخضراء وحفاظاً على البيئة والموارد المتاحة.

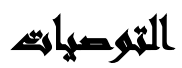

من أجل النطوّر والتحوّل إلى الإقتصاد الأخضر وإلى النشاط والنمو الإقتصادي الذي الذي الني

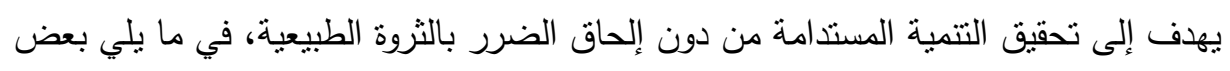
الخطوات لتعزيز هذا التحوّل:

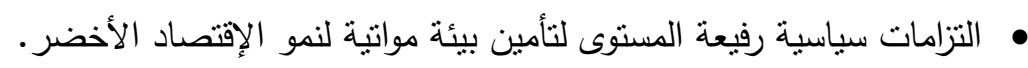

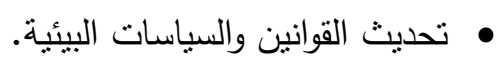
• وضع استراتيجيات وطنية بمواعيد محددة لتحديد الإعتبارات البيئية والقطاعات الجاهزة

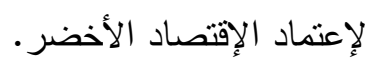
• • وضع حوافز مالية ومادية للأنشطة والسياسات الداعمة للبيئة. • • • • إنشاء لجنة إقليمية لتبادل الخبرات وتبادل المعلومات عن الإقتصاد الأخضر . • تعزيز التعاون بين البلدان فيما يتعلق بتبادل البحوث والخبرات والتمويل والتقنية والتكنولوجية. • ضرورة قيام البنوك بإنشاء نظام لتمويل المشروعات الخضراء ينتاسب مع طبيعة نلك ولك

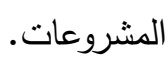
• تقديم تشهيلات ائتمانية للمشروعات الخضراء بسعر فائدة مميز تشجيعاً لتلك المشروعات

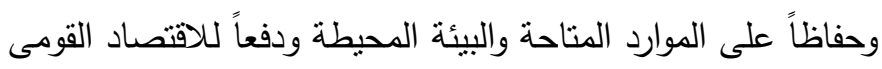


•انشاء وحدة مستقلة بالبنوك لمتابعة مخاطر المشروعات الخضراء والمساعدة فى حل ما

\section{مرائ التراسة}

أحمد الكواز (ع ا • ץ): الاقتصاد الأخضر والبلدان العربية، جسر التتمية، العدد المائة والثامن

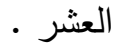

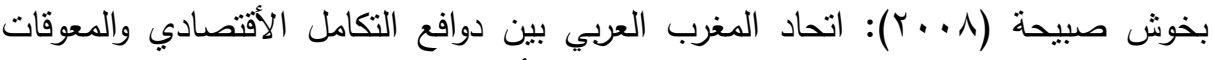

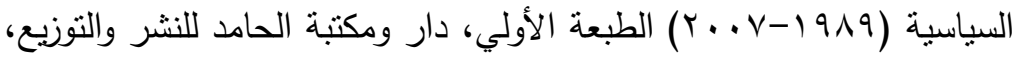

$$
\text { عمان. }
$$

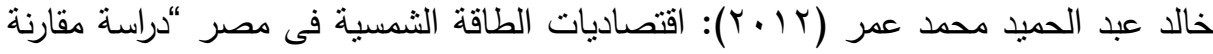
ودراسة قياسية، رسالة دكتوراه ، كلية التجارة جامعة عين شمس .

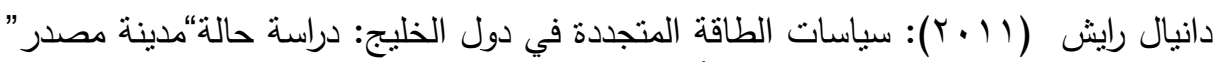

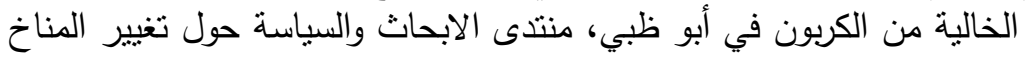

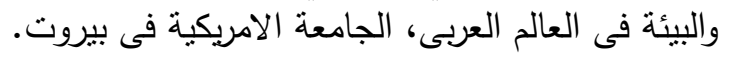

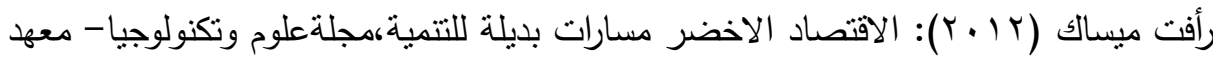

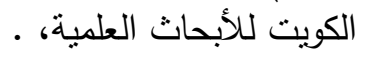

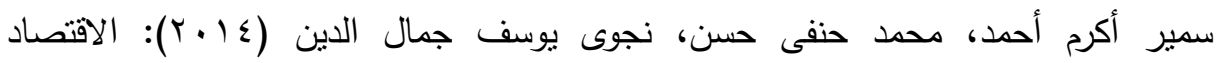

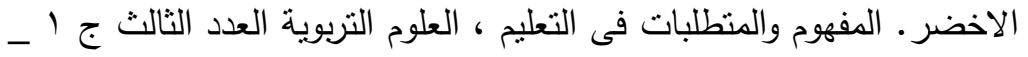

$$
\text { يوليو }
$$

السيد فراج السعيد (10 + ؟): :تطوير الجهاز المصرفى فى اطار التحريرالاقتصادى لدعم

$$
\text { لاستقراروالتتمية. }
$$

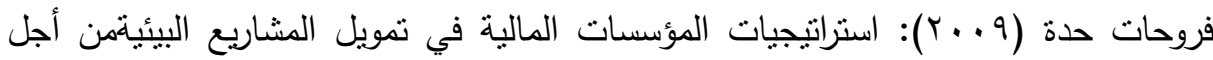

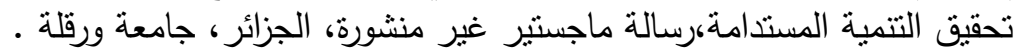

محمد محمود إبراهيم الديب (ب99 1): الطاقة فى مصر، مكتبة الانجلو المصرية . مراد ناصر: التتميه المستدامه و تحديتها في الجزائر، كليه العلوم الاقتصاديه و علوم (بلهيه

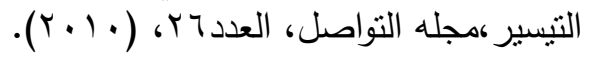




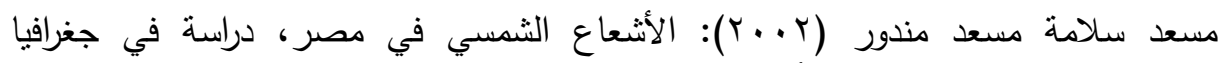

$$
\begin{aligned}
& \text { المناخية، كلية الأداب جامعة المنصورة. }
\end{aligned}
$$

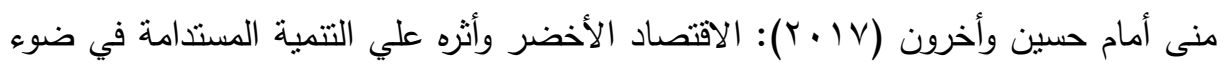

$$
\begin{aligned}
& \text { تجارب بعض الدول، دراسة حالة مصر . } \\
& \text { نوال جمعون (7 ( • ب): دور السوق المالي في تمويل التتمية الاقتصادية المعوقات والآفاق. }
\end{aligned}
$$

Adrian C.Newten \& Elena Cantarello, (2014): An introduction to the green economy (Science, systems \& sustainability), First published, Routledge, New York.

Nora Rathzel \& David Uzzell, (2013): Trade unions in the green economy: Working for the environment, First published, Routledge, USA.

RABEYA KULSUM, S.Sadrul Huda (2018): "Thinking About The Green Banking Model In The Context Of Bangladesh"

Sustainlabour, Green Jobs and related policy frameworks. An overview of the European Union, February 2013. http://www.sustainlabour.org.p28

Yao Wang and Qiang Zhi, (2016): " The role of green finance in environmental protection, Two aspects of market mechanism and policies"

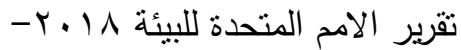

https://www.unenvironment.org/resources/emissions-gap-report- 2018-

https://ebi.gov.eg/research- موقع المعهد المصرى التابع للبنك المركزى المصرى awareness/?lang=ar 
مجلة العلوم البيئية

معهد الدراسات والبحوث البيئية - جامعة عين شمس لئ

\title{
THE ROLE OF BANKS IN SUPPORTING THE GREEN ECONOMY AND GREEN BANKING IN EGYPT
}

\author{
Abd EI Moneim M. I. Elrefai ${ }^{(1)}$;.Abeer F. Ali ${ }^{(2)}$ \\ and Ahmed F. M. Khalil ${ }^{(3)}$
}

1) Central Department of Internal Control, Internal Control Sector, Banque Misr 2) Faculty of Commerce, Ain Shams University 3) Micro Projects and Microfinance Sector, Banque Misr

\begin{abstract}
The study aimed to identify the concept, characteristics and advantages of the transition to a green economy and its relationship with the Egyptian banking system. Green over the coming years. The study concluded that the green economy is the best way to preserve the environment and stimulate economic growth and eradicate poverty. There is a positive relationship between the volume of credit in the banking system and the volume of credit directed to green projects. The researcher made several recommendations, the most important of which are: The need for banks to establish special systems to finance green projects commensurate with the nature of these projects and the establishment of new banking products in the so-called (green banking). Appropriate, with the establishment of a new specialized department to monitor the credit risk of green projects and take appropriate measures to detect any risks that may face these green projects.
\end{abstract}

Keywords: Banks - Green Economy - Green Banking

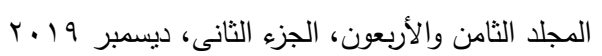

